University of Redlands

\title{
A Water Utility Mapping Application for the City of Elko, Nevada
}

\begin{abstract}
A Major Individual Project submitted in partial satisfaction of the requirements for the degree of Master of Science in Geographic Information Systems
\end{abstract}

\author{
by \\ Alejandro Quintero \\ Mark Kumler, Ph.D., Chair \\ Maxwell Baber, Ph.D. \\ Mark Stewart
}

August 2008 
A Water Utility Mapping Application for the City of Elko, Nevada

Copyright $(\underset{2008}{2}$ by Alejandro Quintero 
The report of Alejandro Quintero is approved.
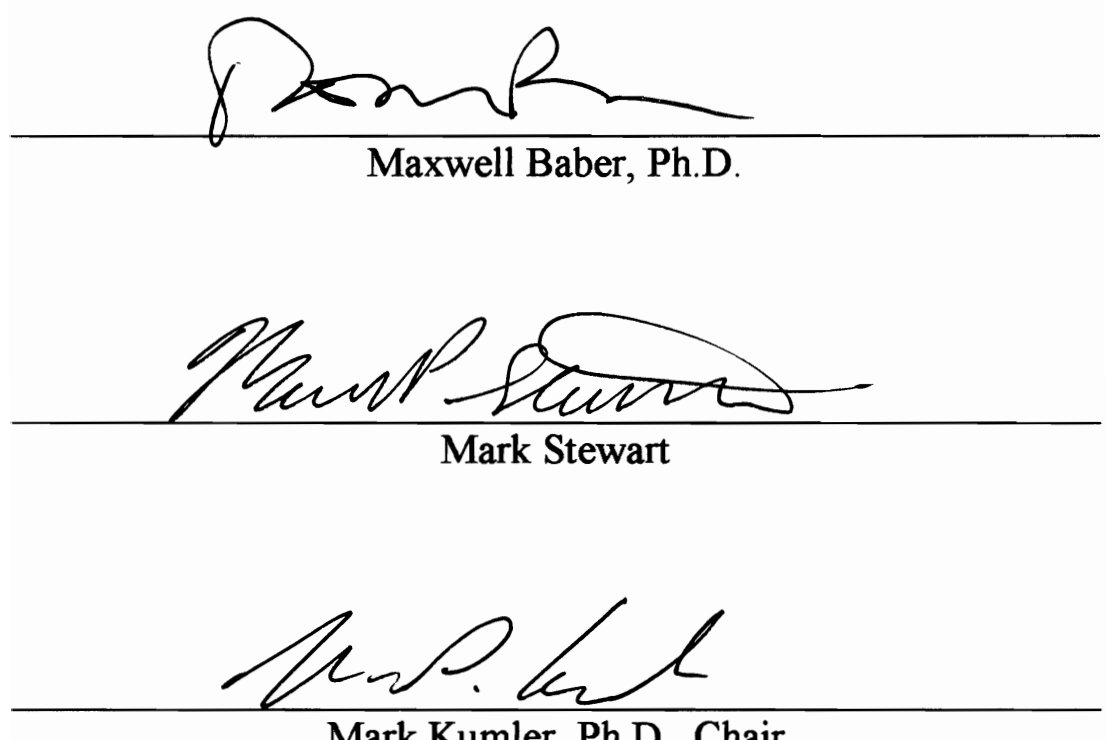

Mark Kumler, Ph.D., Chair

August 2008 



\section{ACKNOWLEDGEMENTS}

The following people have helped support me throughout the past year.

Louise and Arturo Quintero, my loving mother and father who have always been there for me and who have been my biggest supporters. They have always shown faith in me and provided me with the moral support I needed to complete this program. Without their support none of this would have been possible.

To my closest family members uncles, aunts, cousins, sisters, and grandparents who have always been there for me. Thanks to my uncle, Refugio Quintero, who has helped me throughout my life by encouraging me to get a college education and personally educating me with his own experiences in life. Thanks to my padrino, Pedro Quintero, for always encouraging me and providing me with moral support.

I would like to especially thank my advisor Dr. Mark Kumler for his help and guidance during the past year of work on my MIP. Dr. Kumler kindly took the time to help me accomplish my MIP by adding in those extra weekly meetings and providing me with feedback and resources I needed. His help and guidance helped me achieve my goal in completing my MIP and receiving a M.S. GIS Degree here at the University of Redlands.

To the members of the University of Redlands MS GIS program. Thanks to my committee members Dr. Maxwell Baber and Mr. Mark Stewart for providing their time, help, and support in the process of completing my Master's project. I would like to thank Brandon Davis for helping me with my computer issues and fixing the errors that plagued my Dell. Thanks to Theresa Ellis for all her help and guidance throughout the year.

Mr. Tony Ferguson, my client, for providing me the opportunity to work with him this past year. Mr. Ferguson has provided me with his time and patience needed to complete my MIP project. He was always available when I needed him and he always managed to provide me with the resources I needed to complete the project.

A special thanks to all my fellow colleagues who were there for me during the good and bad times. To my friends Melissa Gasparich, Stephen Benzek., and Daniel Smith with whom I have grown and learned with over the past year, we all struggled to get through the program but we conquered the obstacles and together pushed each other to accomplish what seemed to be a never ending story. 



\author{
ABSTRACT \\ A Water Utility Mapping Application \\ for the City of Elko, Nevada \\ by \\ Alejandro Quintero
}

This project explains how a small town in northeastern Nevada improved the collection of data for the local water utility department with the use of a GIS. The initial need was to improve and expand the city's existing GIS data holdings by incorporating ESRI's ArcGIS product to accommodate the mapping needs of the Engineering and Municipal Water Departments. The collection of data into a GIS is used to find, improve, and reduce time spent on researching for information needed for planning and decision making. Data assessment and conversion comprised a major portion of the project. The database design was modified with the use of an existing water utility data model based on the assessment provided by the client. The software design for the project utilizes outof-the-box ArcGIS 9.2 tools and functionality. The use of a geometric network was implemented to execute trace analysis on the water network available with use of the Utility Network Analyst toolbar. The importance of using GIS for the water utility department has proven to be more than a pretty map but rather a tool that can be used to solve problems when they arise which helps save time and money for the community. 



\section{Table of Contents}

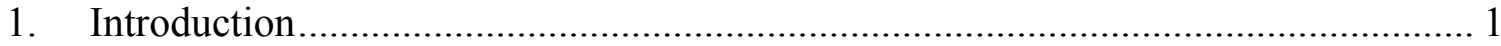

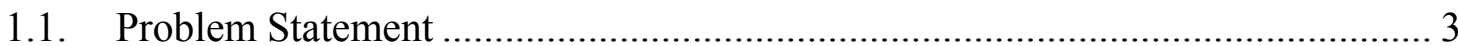

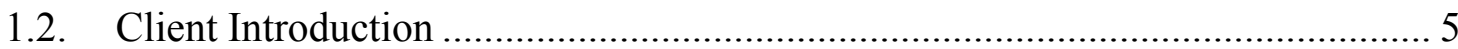

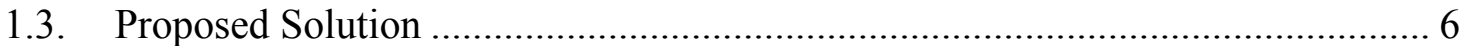

1.4. Background and Literature Review.............................................................. 7

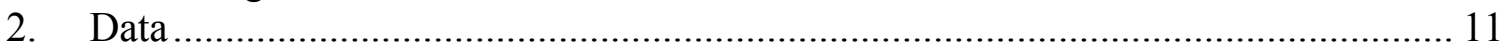

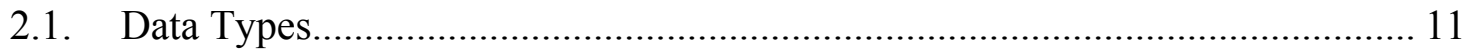

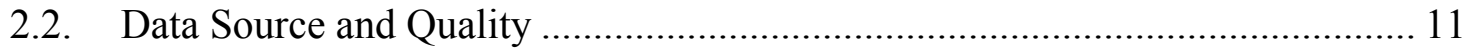

2.3. Data Preparation and Manipulation............................................................... 11

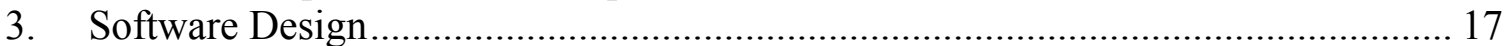

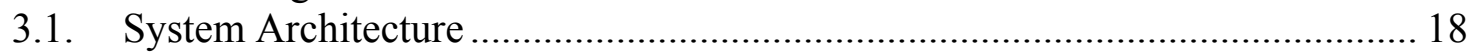

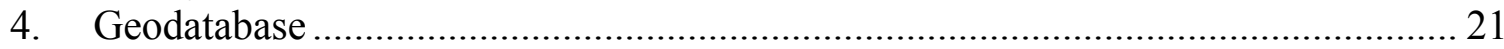

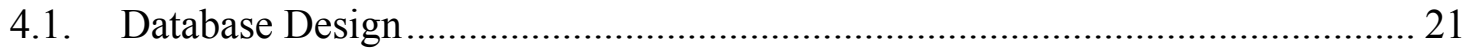

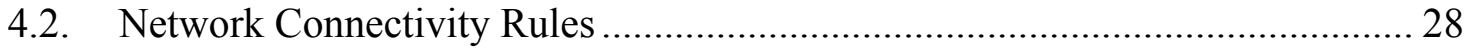

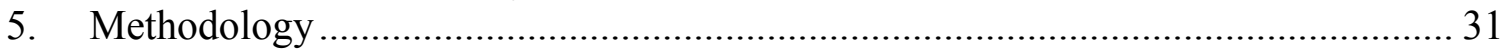

5.1. Performing Trace Analysis on Network......................................................... 31

5.2. Trace Analysis Operations ............................................................................ 31

5.3. Tracing for Connected Features ...................................................................... 32

5.4. Tracing for Disconnected Features ……………………………………….... 33

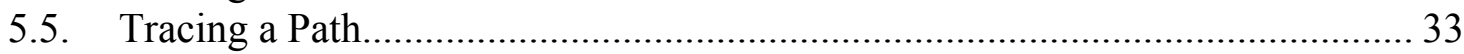

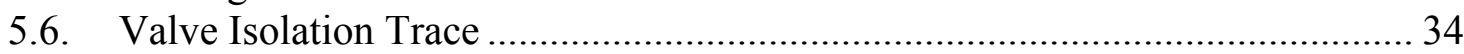

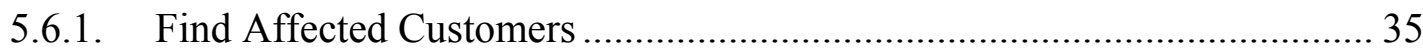

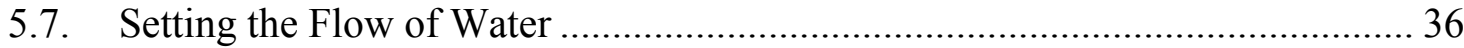

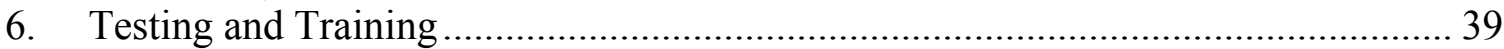

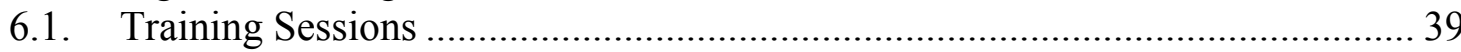

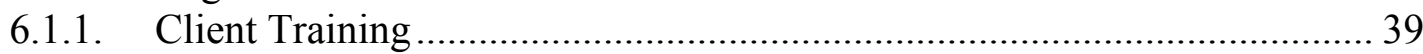

6.2. Reference Materials...................................................................................... 40

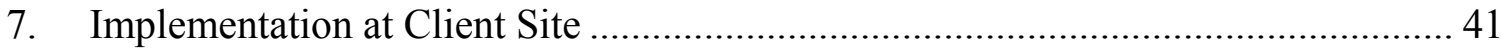

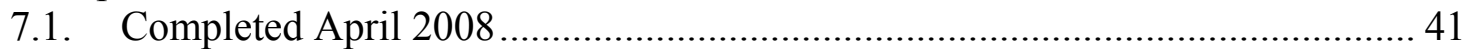

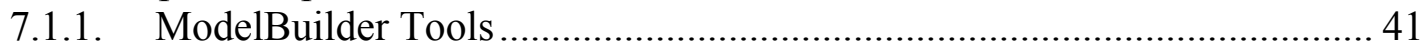

7.1.2. Configure Out-of-the-Box Tools .............................................................. 43

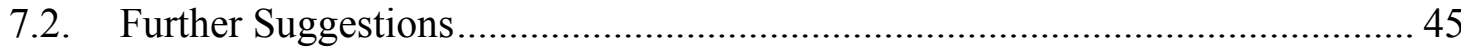

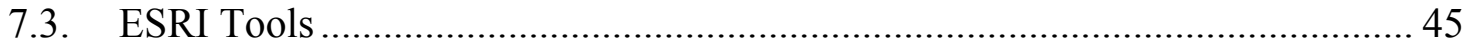

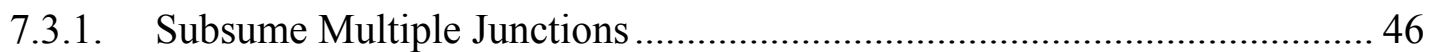

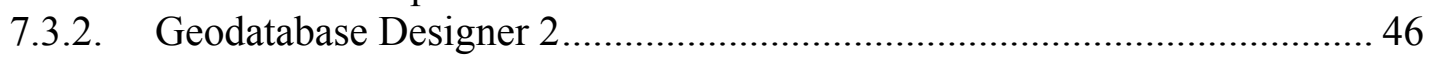

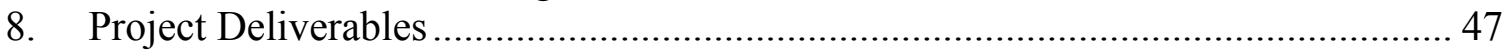

8.1. Introduction and Purpose ……….............................................................. 47

9. Summary and Future Work............................................................................ 49

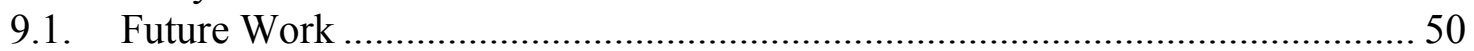

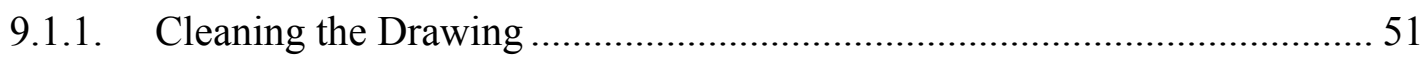

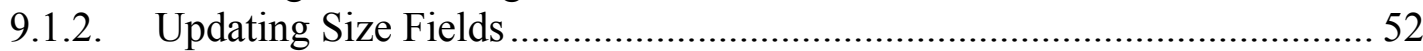

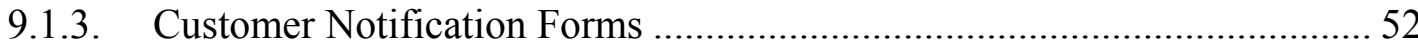

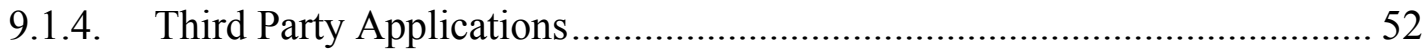

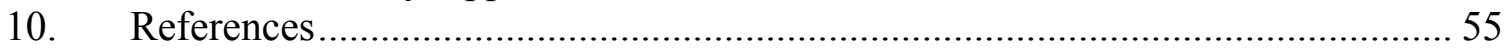

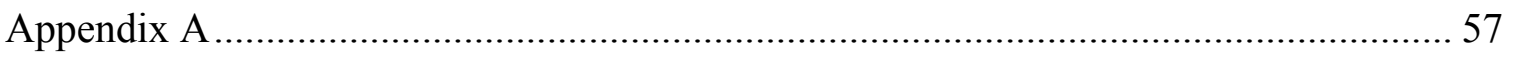




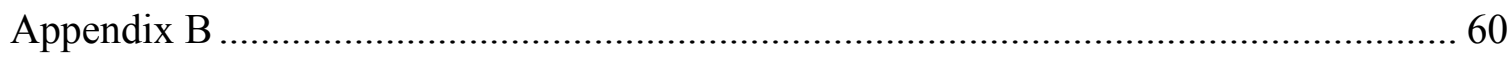

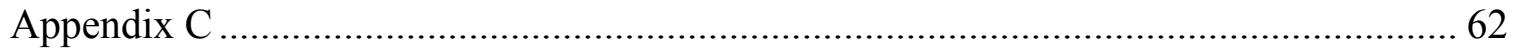

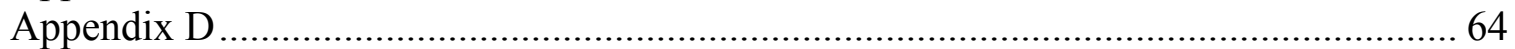




\section{Table of Figures}

Figure 1-1. Distribution of Earths water supply (U.S. Geological Survey, 2008)............. 1

Figure 1-2. The City of Elko municipal departments interested in GIS ........................... 4

Figure 1-3. Location of Elko, Nevada ……………….............................................. 5

Figure 2-2. Coordinate system created for base AutoCAD data .................................... 13

Figure 2-3. Geoprocessing model for extracting and appending data to geodatabase..... 14

Figure 2-4. Hyperlink to an as-built document from selecting an active feature ............ 15

Figure 3-1. Work-flow procedure for maintaining the GIS .......................................... 18

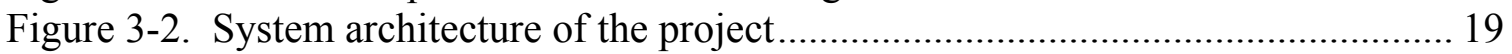

Figure 4-1. Complete detailed version of water utility data model ................................. 22

Figure 4-2. Generalized geodatabase of the water utility data model............................. 22

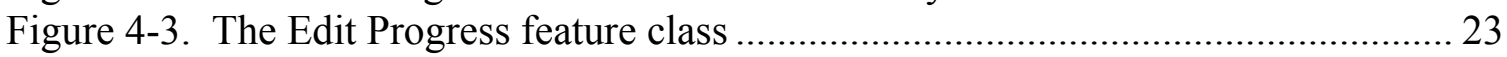

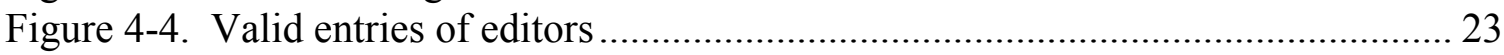

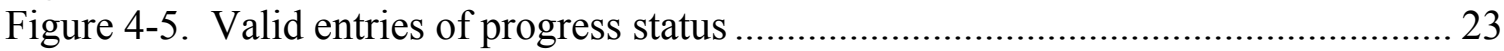

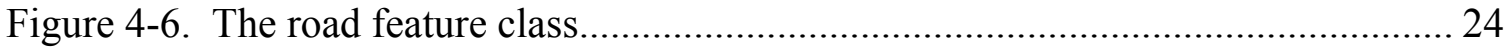

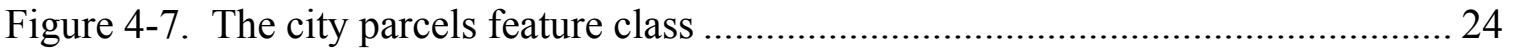

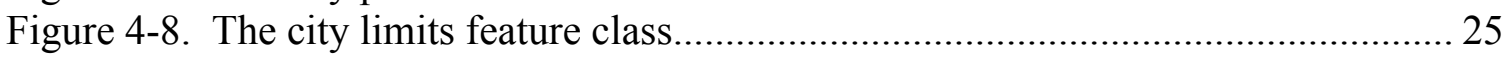

Figure 4-9. The pressure water zones features class ................................................... 25

Figure 4-10. Valid values of pressurized water zones ................................................ 25

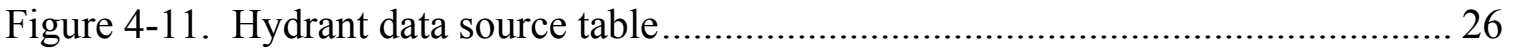

Figure 4-12. Hydrant relationship description .......................................................... 26

Figure 4-13. Photo uploaded in raster field of hydrant feature ......................................... 27

Figure 4-14. Water features dataset and feature classes ................................................ 27

Figure 4-15. Water Network dataset, feature classes, and the geometric network .......... 28

Figure 4-16. Example of edge-edge rules applied to network ......................................... 29

Figure 5-1. Location where network traces were executed ............................................. 31

Figure 5-2. Results of trace task to find connected features ........................................... 32

Figure 5-3. Results of trace task to find disconnected features ......................................... 33

Figure 5-4. Results of trace task to find the path from two points.................................... 34

Figure 5-5. Results of tracing to identify valves to be closed....................................... 35

Figure 5-6. Results of tracing network to find customers affected due to valve closure. 36

Figure 7-1. Custom tool to set the water zones of features............................................ 42

Figure 7-2. Custom tool to clip county to city parcels................................................... 43

Figure 7-3. The Geometric Network Editing toolbar.................................................... 43

Figure 7-4. Tool used to extract data from parcels to service connections....................... 44

Figure 9-1. Arcs and orphan junctions that should be removed in drawing ....................51

Figure 9-2. Diameter reference for tee fitting .......................................................... 52

\section{List of Tables}

Table 2-1. AutoCAD layers added to geodatabase......................................................... 12

Table 9-1. Update count of GIS data layers as of June, 24 2008................................... 50 


$\begin{array}{ll}\text { List of Acronyms } \\ \text { APN } & \text { Assessor Parcel Number } \\ \text { CAD } & \text { Computer-Aided Design } \\ \text { CMMS } & \text { Computerized Maintenance Management System } \\ \text { EMWD } & \text { Elko Municipal Water Department } \\ \text { ESRI } & \text { Environmental Systems Research Institute } \\ \text { GIS } & \text { Geographic Information System } \\ \text { GASB } & \text { Government Accounting Standards Board }\end{array}$




\section{Introduction}

One of the key essentials of life is water. When studying the Earth from space or a world map, there appears to be an abundance of water resources available for use. In reality, about 97 percent of all water on Earth is contained in the oceans, with only three percent existing as fresh water (U.S. Geological Survey, 2008). Of the fresh water, 68.7 percent is stored in glaciers and ice caps. Underground water accounts for 30.1 percent and the remaining 0.9 percent is stored in lakes, rivers and swamps as illustrated in Figure 1-1 (U.S. Geological Survey, 2008). This illustrates the need for better water management to preserve the limited quantity of fresh water that exists on Earth. This project demonstrates the importance of a Geographic Information System (GIS) in managing information of a domestic water system for a small community in northeastern Nevada.

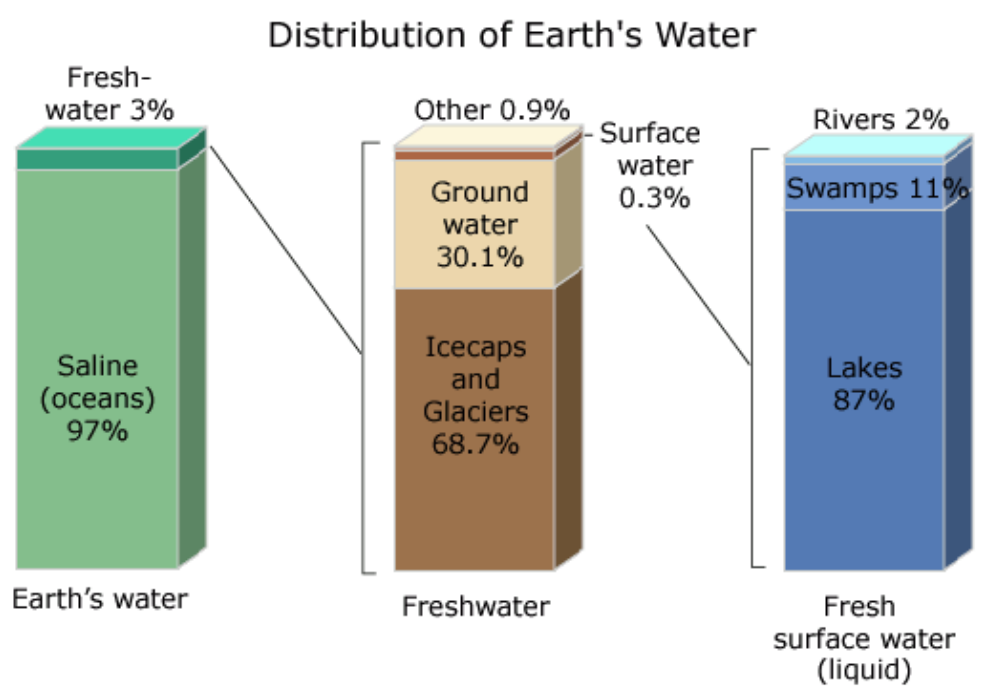

Figure 1-1. Distribution of Earths water supply (U.S. Geological Survey, 2008)

It is necessary to improve the management of the supply of water to help sustain the supply and demand of water resources. Homes, communities, businesses, farms, and cities require a regular supply of water from functioning natural and human delivery systems (Wilson, Mitasova, \& Wright, 2000). Water infrastructures must be continually maintained to preserve the network that provides service to customers (National Research Council, 1996). The majority of existing water infrastructure systems in the U.S. were built over 50-100 years ago and they have begun to outgrow their original design capacity (Shamsi, 2005). A GIS can provide the tools to better maintain records of aging infrastructures, which in turn assists in planning, organizing, and executing sound decisions.

Historically, storing accurate spatial information has caused problems for many U.S. government agencies. The growing concern about deteriorating infrastructures in the U.S. creates a need to provide accurate and detailed information about the state of these facilities (National Research Council, 1993). A GIS can provide the ability to maintain information for facilities management and operations. 
GIS are used by municipalities and water authorities to more effectively manage their water utility infrastructure. Typical requirements of the water utility industry include:

- Updating GIS databases with as-built data

- Integrating computer aided design (CAD) drawings into the GIS environment

- Managing operations activities, such as leaks, repairs, and inspections

- Analyzing installed networks for planning and capital improvement projects

- Producing standard and custom map products

The maintenance and operations of the water industry are met with the use of a GIS by integrating data sources and providing information on-screen for the user (ESRI, 2001). The integration of data sources into the GIS provides the ability to make better decisions and provides confidence in the dataset's accuracy as to what is actually in the ground.

City employees of Elko, Nevada, have had numerous issues concerning information about their own local geography. The questions asked relate to the spatial locations of information such as:

- How many people live in a particular neighborhood?

- Who will be affected by the new water main replacement?

- Where are the gas and water utilities located?

- How can the city reduce research and analysis time currently directed towards busy engineers?

The use of a GIS can provide reduced time and loss of money by storing geographic data layers (e.g., cadastral, transportation, facilities) in a geodatabase. Information can then be distributed and shared through a local government intranet. Selected data can be distributed to the public via the Internet.

The City of Elko wishes to improve and expand its existing GIS data holdings by incorporating ESRI's ArcGIS product to accommodate the mapping needs of the Engineering and Municipal Water Department. The Engineering Department is currently tasked with maintaining the majority of digital drawings for the city, including those of the domestic water network, in AutoCAD. Providing city engineers the ability to maintain well kept records in the ArcGIS environment will assist them and the Elko Municipal Water Department (EMWD) employees in retrieving and viewing detailed information about its domestic water utility facilities. With GIS, the city can serve its customers better as it continues to develop, maintain, and plan for future uses (ESRI, 2003). GIS will improve the way data is stored and maintained, replacing inefficient AutoCAD and paper maps as the main method of storing information.

Until 2008, the city's water utility infrastructure digital records were maintained in AutoCAD format, which maintains little or no significant information that is otherwise stored in tables, scanned images, or field notes. The data stored in AutoCAD format does not include any topological rules associated with the vector data, such as proper snapping or connectivity rules that relate to the water infrastructure's system physical design. Converting the existing data from its current AutoCAD .DWG drawing format into an ESRI geodatabase, using a predefined water utilities data model, prepared the data files for use in GIS. The data model helped structure the geodatabase design and served as a 
blueprint for the city engineering department for storing relevant information about the domestic water network, such as install date, material type, size, and work order ID's.

\subsection{Problem Statement}

The City of Elko wished to improve and reduce time spent on researching for information. The problem began with data not being well documented and the data available was being stored in various formats and locations. In particular, there are cases in which information was located throughout different departments or various folder files. Drawing files in particular were located on local computers and on the local server, which created confusion about the data files' relevance. Paper maps were located throughout various locations, such as in large cabinet files, employee offices, and multiple buildings that made information difficult to locate. These data files have constrained information for the client, due to their inabilities to capture and store large amounts of attribute information, needed for planning and maintenance of the water network.

Data stored in AutoCAD format were updated by the Engineering Department who then provided the drawings to other departments upon request. Data derived from paper maps took hours or even weeks to gather in order to acquire information needed to provide customers, developers, or the State. The need to develop a GIS database would centralize data and allow various users within the city to share needed information easily. Data management is essential to the architecture of the system in order to reduce data replication and to encourage a data sharing environment between the city departments. The construction and use of a functional GIS for any city is considered a necessity to help improve services provided to its citizens, which in return saves money and improves the quality of life of the community (Fleming, 2005).

Municipal departments within the City of Elko - including Planning, Police, and Fire all expressed an interest in applying GIS to their current work-flow procedures (see Figure 1-2). Creating a complete database design for the City of Elko in and of itself is too large a project for a one-year master's-level project. This project addresses the effort of implementing a GIS for the city by focusing on the needs of the EMWD. The decision was based on existing domain knowledge of the water utility industry and the potential benefits that GIS can provide the department. The focus on implementing a GIS application specifically for the EMWD addresses the efforts of future GIS endeavors the city may pursue. The data on record for the local water utility department are primarily stored in paper format and maintained digitally in an AutoCAD drawing environment. 


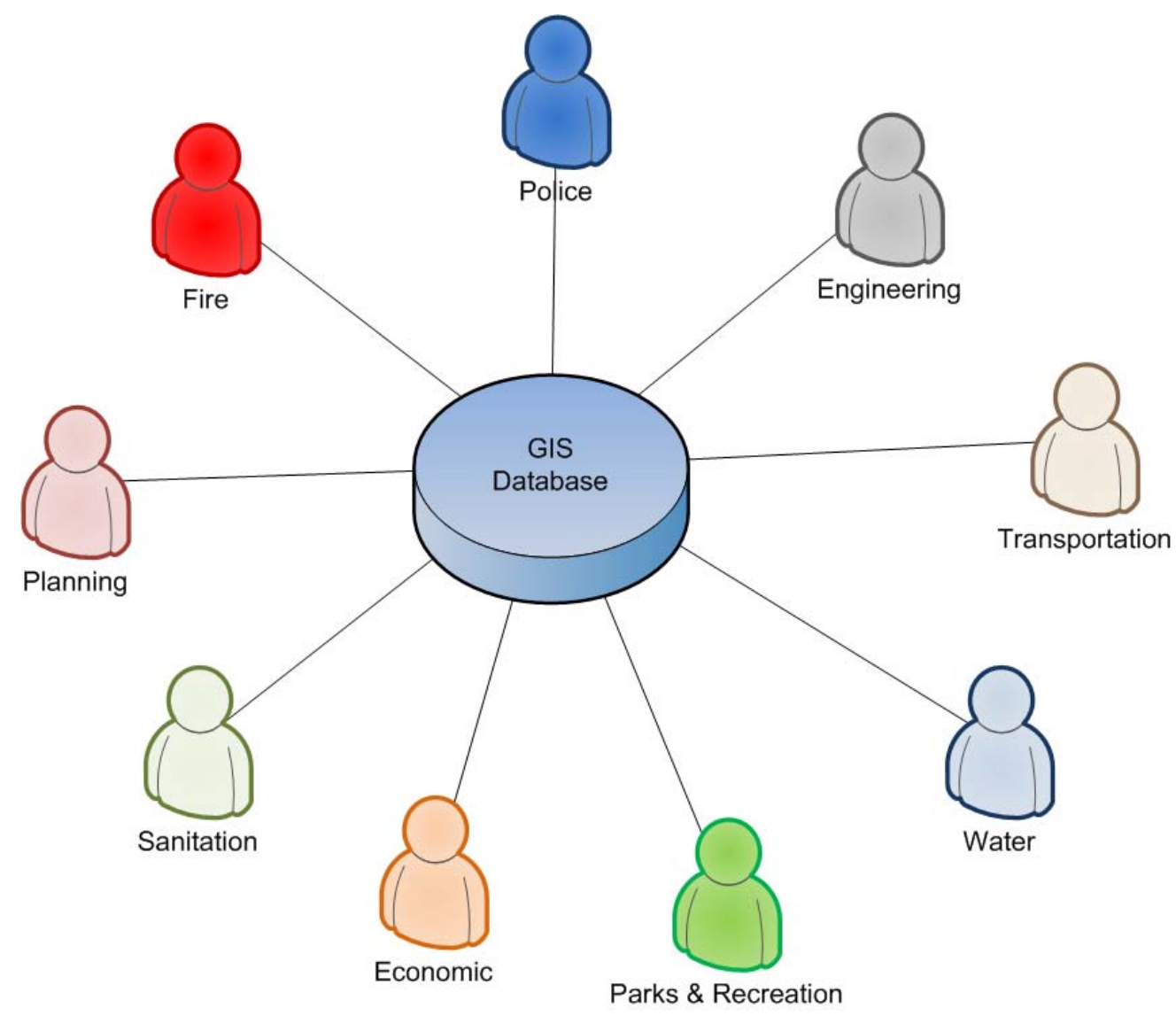

Figure 1-2. The City of Elko municipal departments interested in GIS

The CAD data maintains little or no significant attribute information associated with it. This is often referred to as "spaghetti data" — data composed of lines with no topological rules or attribute information - and it is not an efficient way to store and maintain the utility's assets. Information is not being distributed effectively as it is limited to savvy AutoCAD users who have direct access to information. The CAD data that are distributed are not understood well by the consumers, and this often creates more questions. Detailed information about individual network facilities, such as material type, segmented mains, and install dates, are not being stored or captured in the CAD system. These are common attributes that are important for maintaining the water distribution system in order to keep an up-to-date inventory of the utility's assets.

Other pertinent information about the water facilities is too often stored in the memory of employees; this also needs documentation. It will be necessary to involve those experienced staff members in the data creation and verification processes to populate attribute records for the water network facilities. The GIS application for the utility department will help improve work-order tracking, field locating, and provide better services for the community. 


\subsection{Client Introduction}

The client is the City of Elko, Nevada, a small community situated midway between Reno, Nevada and Salt Lake City, Utah, along Interstate 80 (see Figure 1-3). The city's population is about 16,980 residents (U.S. Census Bureau, 2006) and it is the seat of Elko County. Elko's main industries - mining, ranching, and outdoor recreation - continue to add to the community's well being.

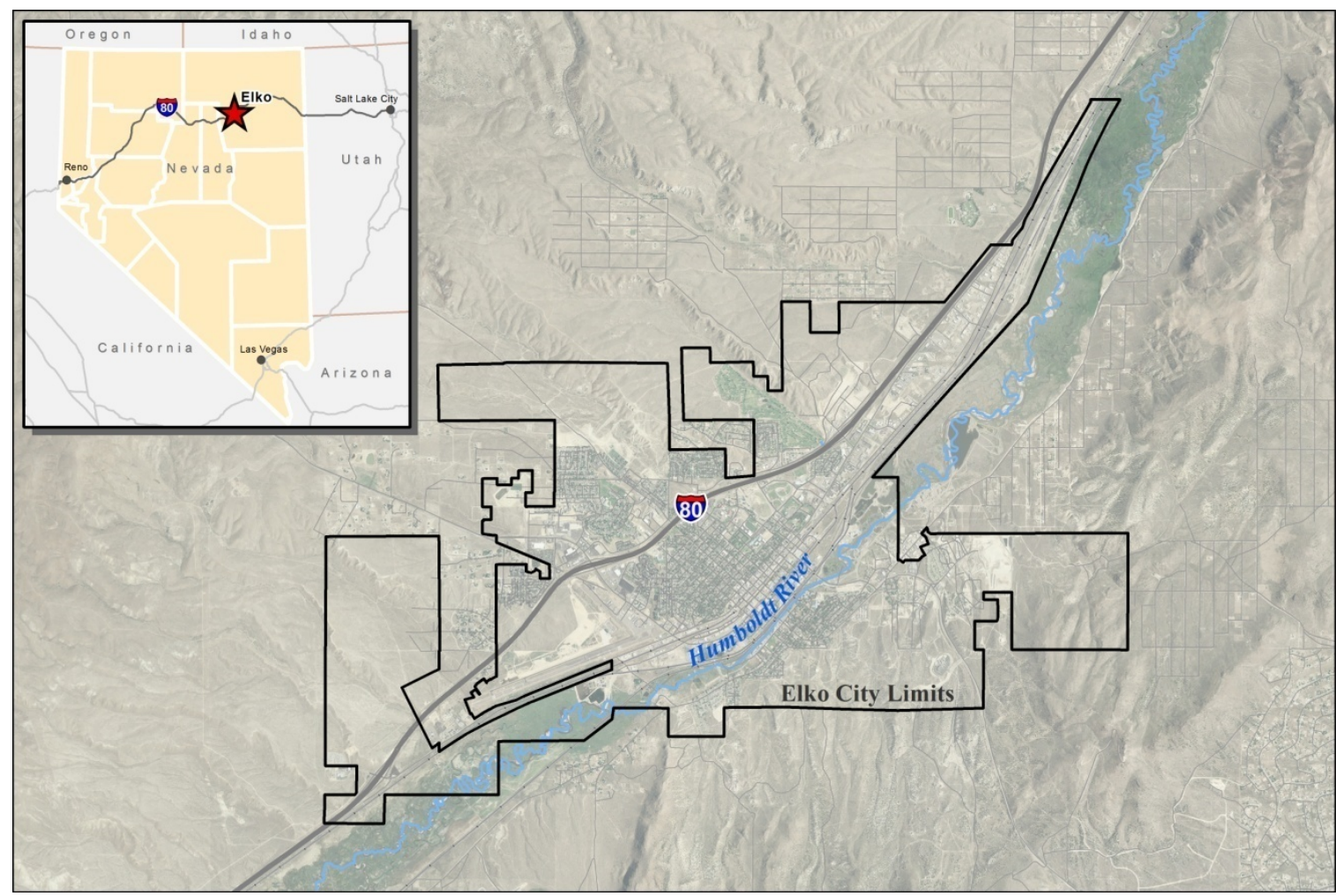

Figure 1-3. Location of Elko, Nevada

The EMWD is the local water utility provider that focuses on serving the residents of Elko, Nevada, with the highest quality water supply. They continually plan for future water resources and focus on the delivery capabilities through existing infrastructure. The EMWD's domestic water supply system includes over 174 miles of distribution pipe and more than 5,100 service connections. Underground water is the main source of water that the EMWD provides to its customers.

The main point of contact for this project is Mr. Tony Ferguson, the city's Senior Engineering Technician. Mr. Ferguson has provided guidance, data, and his understanding of the water industry. He maintained an open communication that has allowed this project to succeed. Mr. Ferguson and the city would eventually like to integrate GIS to store spatial information that can be analyzed, queried, and easily updated. The GIS database will help promote the initiative to other departments to use GIS to enhance their business procedures. 
The city's future GIS projects will be led by Mr. Ferguson. He plans to eventually create an enterprise GIS that includes all departments at the city, making data available to those employees who need the data. The completion of this project will assist Mr. Ferguson in his endeavors to move the city in a positive direction for implementing an enterprise GIS and provide a means to demonstrate to others how GIS provides solutions for creating, storing, and analyzing information.

The overall purpose of the project is to continue building and improving on the city's existing GIS to incorporate new theories and technology in the process. The scope of this project focuses on integrating GIS for the EMWD which provides them with the necessary tools to maintain the maintenance and operations of the domestic water utility network.

\subsection{Proposed Solution}

The first step in creating a database design for the city is to properly assess the available data. Once a final assessment is delivered, a conceptualized model will reflect the results extracted from the client's assessment. Using the assessed data, the system architecture will be defined. The existing ESRI water utilities data model (ESRI, 2008a) will be modified based on the needs assessment provided by the City of Elko and an assessment prepared by Sunrise Engineering. The database structure, features, relationships, fields, and domains will be modified to suit the client's assessed needs. A physical database model will then be created. The physical database model will serve as the data repository where the data will reside. The physical database includes a geodatabase with coded domain values, feature datasets, feature classes, a geometric network, and relationship classes preset for the feature data sets.

Since the majority of data resides in a non-geodatabase format, the first step will be to convert the data for input into GIS. Geoprocessing tools and toolbars available in ArcMap and ArcCatalog will provide the capability of converting the data's format. An important reason why data is converted to GIS is so that the data is in the same coordinate system as the GIS data layers (Mattix, 2006). Careful planning and testing will ensure high quality output from the project.

Once the final geodatabase is completed it will be populated with geographic data files. Data sources, such as CAD files, scanned paper maps, an Excel document, and experienced field crew members will provide the primary source of information to update attribute information. These data sources provide the bulk of data needed to update each the network facilities.

Data can then be analyzed to check connectivity rules in the network. This will allow the user to edit data in the network to ensure that there is connectivity throughout the water network facilities. The process of analyzing connectivity in the network can be found using the Utility Network Analyst toolbar. The toolbar allows users to perform trace operations on the current network, such as finding connected and disconnected features. The use of the Utility Network Analyst toolbar will provide the client with the tools to monitor Quality Assurance and Quality Control (QA/QC) of data when editing in ArcMap. 
Discoveries made during the course of this project to incorporate or update business procedures will improve the collection of information for the city. Data sources, such as knowing the municipal departments that receive information about the maintenance of the water network need to be identified to capture that data in the GIS database. Since data will continue to be submitted in paper or CAD format, the integration of those data files need to be structured so that they can be converted within the ArcGIS environment easily. Eventually, CAD plans received from engineering firms will be sent to the city for approval and be required to follow standards that will simplify the process for city officials to use the data in ArcMap. As-built plans that are in paper format will need to go through a scanning process in which a naming convention will be applied to make them easy to locate. The GIS application to be implemented will have to meet the client's specific needs; the benefits shall highlight the importance for this new system integration.

\subsection{Background and Literature Review}

The challenges associated with using GIS to update services and management processes at the EMWD are not uncommon. Mercer Island, Washington, and Bellingham, Washington, are examples of cities that use GIS to manage their water distribution systems. Their accounts include problems and issues they encountered before and after the implementation process of a GIS. These reports, along with many other related case studies, can be found in ESRI's Water Writes Newsletter (ESRI, 2008b). The cost of implementing GIS is another factor examined to better understand the implications for an organization trying to implement GIS.

Mercer Island, Washington, is a small town located between Bellevue and Seattle with a population of approximately 21,000 residents (ESRI, 2002). City officials had a difficult time trying to initiate a GIS until they hired a GIS Coordinator to carry the workload needed to implement a successful GIS. After the GIS was established, the workload for maintaining it proved to be too much for one GIS coordinator. City officials hired a GIS Analyst to collect data and maintain the GIS. Designing a geodatabase was very difficult for the GIS Analyst, as he did not utilize the existing ArcGIS data model as a starting point. The Analyst then turned to Microsoft Visio as he believed it would be useful in maintaining the growing data model because of its ease with changes to the data model compared to using off the shelf ArcCatalog (ESRI, 2002). The uses of existing industryspecific data models available from ESRI provide the building blocks for data models instead of re-inventing the wheel. For Mercer Island, having a GIS leader, incorporating existing data, and creating a geodatabase became the main problems in the initial stages

of building a GIS, but with a GIS staff, better planning and organization their GIS project was completed successfully.

The City of Bellingham, Washington, implemented a GIS that accommodated the existing infrastructure and unexpected growth (ESRI, 2003). City officials faced many obstacles in the process of creating a stable GIS application. They began their initial GIS to produce a mapping reference with the enormous collection of tabular data used throughout the city. The tabular data was linked with the parcel data from the county assessor, record by record. The second phase linked the utility spatial data to the tabular asset database. This task consisted of extensive hours of converting infrastructure 
information from tabular data into the GIS (ESRI, 2003). These are procedures that were undertaken by the City of Bellingham to link existing data from the county to spatial data that the city maintains. These procedures helped simplify and enhance the quality of life by reducing workloads of busy employees. Integrating existing data with GIS provides users with a wealth of information without having to recreate the data.

The cost of implementing GIS into any organization can be expensive and a return on investment may take years to achieve (Shamsi, 2005). So how does an organization find sufficient funding for a GIS project? How can costs be mitigated? Other issues such as data conversion, data management, and data sharing must be addressed prior to accurate locating and mapping of network infrastructures. Maintaining high quality records of all network facilities allows managers to properly manage infrastructure assets (Water Environment Federation, 2005). Nevertheless, there have been many U.S. cities, such as San Diego, Boston, and Knoxville that have successfully integrated GIS into their daily operations with proper planning and a GIS leader.

A primary concern for industries trying to implement GIS is the maintenance of longterm funding and support from the senior management (Tomlinson, 2007). There are certain key drivers that motivate improved asset management, such as the federal Government Accounting Standards Board (GASB) 34 (Shamsi, 2005). GASB 34 was adopted in June 1999. It established financial reporting standards for state and local governments that include a full accounting for all capital assets including government's infrastructure (Nevada Department of Transportation, 2008). GASB 34 requires government entities to "properly account for and report capital asset inventory in a complete, accurate, and detailed manner" (Shamsi, 2005, p. 312). Providing improved solutions for asset and inventory management of infrastructures reports, such as the GASB 34, encourage local agencies to become better stewards of their infrastructure (Governmental Accounting Standards Board, 2000). The commitment of senior management is vital for the success, planning, and implementation of a GIS project. The enhancement of utility mapping is a principal goal of a successful GIS, providing longterm savings in time and money.

Steps for extracting and transforming data are among the most expensive and time consuming tasks in GIS implementation. According to the Mohawk Valley Water Authority of Utica, New York, estimated that approximately 75 percent of GIS costs are directly related to data conversion and creation (DeGironimo, 2002). Pidpa, a Belgium company, is another water agency that did a major conversion from paper to a digital format. They scanned, processed, and then saved the scanned paper maps in a georeferenced file structure. The scanned digital files were then available to Pidpa's agency in a single, seamless raster that could be viewed in the GIS environment (Bedford, 2004). Data conversion and manipulation are among the issues addressed by this project.

The City of Elko is one of many small towns that understand the benefits of GIS but lacks full support from senior management in order to provide sufficient funds to integrate a citywide GIS. Since sufficient funding is not available, the city is unable to perform a full implementation of GIS, but it is interested in implementing a preliminary GIS (T. Ferguson, personal communication, September 24, 2007). As of December 2007, the city has two ArcInfo and three ArcView licenses, and it anticipates expanding 
those services by adding at least three more ArcView licenses in late 2008 (T. Ferguson, personal communication, May 2, 2008). The ArcView licenses will enable others from various departments to view spatial information. Once other city employees begin to see the value of GIS, the goal will be to include every department in the budget to provide financial support for an enterprise GIS.

Creating a strategic plan to implement GIS has its problems, such as training staff members and modifying work-flows. The use of GIS must satisfy the needs of the consumer, rather than being technology driven. GIS or any other new technology should be used and adopted because it will meet the requirements and well-defined needs of the organization (Benjamin \& Khawaja, 1996). The City of Elko has provided the incentive to use GIS to enhance the collection of geospatial information and manage the dissemination of data. Data dissemination is a step forward in implementing GIS, but there may be instances in which people may not clearly understand the logic behind the technology.

The power of GIS needs to be reinforced at a level in which people understand why they are using the technology in the first place. GIS is often understood as large-scale operations with high initial costs, usually financed at the federal or state levels. The main purpose of the GIS is to help politicians and bureaucrats make sensible decisions in the management of natural or human resources (Muller, 1985). The final completion of this project will provide the client with the ability to use GIS and its out-of-the-box tools to perform analysis on their data. 



\section{Data}

The client's desire to provide ongoing support of four different input data sources-CAD files, shapefiles, scanned paper maps, and Excel documents-was a major challenge in this project. The data used for the project were supplied by Mr. Tony Ferguson of the Engineering Department for the City of Elko. The data files were converted from their original format for inclusion in an ESRI file geodatabase. The data were exported and stored in an ESRI file geodatabase with the "State Plane Nevada East FIPS 2701 Feet" projected coordinate system and a North American 1983 datum.

\subsection{Data Types}

The data types used for this project are described as follows. A few synoptic CAD files - the Master Utility and Fire Hydrant Location drawings - used by the client to update and reference network facilities provided the largest source of data. The CAD drawings provided information in the form of polyline, polygon, point, and annotation layers with information associated with all of the water facilities. Shapefile data included point information for service connections originally created from the Master Utility CAD drawing, provided with no metadata. The scanned paper maps are as-built drawings that include detailed information about the water facilities. An Excel table included a compilation of hydrant information.

\subsection{Data Source and Quality}

The two main CAD files used in this project, the Master Utility and Fire Hydrant drawings, included information that had been collected and recorded in digital format by the Engineering Department over the past 10 years. Engineers employed previously by the city had maintained the CAD drawings, and they are currently updated by Mr. Ferguson. The CAD drawings include utility information on the domestic water, sewer, and storm drain facilities. Other CAD drawings provided for the project are referred to as as-builts. As-builts are submitted to the city by external engineering firms once project work is completed in the field and the final plans are reviewed for approval by the Engineering Department. These drawings include detailed utility information, typically at a 1:600 scale. The hydrant data provided by The Elko Fire Department included fire hydrant data that is kept up-to-date in a software application called FireHouse. The data from the hydrant table includes test rates, location, material, and status of each hydrant.

\subsection{Data Preparation and Manipulation}

Steps taken to move the project forward consisted of sorting through the data provided by the City of Elko to assess the information. The most complete digital file of the domestic water network provided in digital format was in a .DWG drawing file, which is an AutoCAD drawing file. The CAD data includes points, polygon, polyline, and annotation information that are read by ArcGIS without any manipulation. The ability to view the CAD layers in ArcMap is beneficial to assess and identify the data layers needed for extraction to GIS. The CAD data layers used for this project are identified in Table 2-1. 
Table 2-1. AutoCAD layers added to geodatabase

\begin{tabular}{|c|c|c|c|}
\hline $\begin{array}{l}\text { Layer name in } \\
\text { AutoCAD }\end{array}$ & Geometry & $\begin{array}{l}\text { Number of } \\
\text { features }\end{array}$ & Data source \\
\hline WATER-SERVICE & Point & 1122 & $\begin{array}{l}\text { UTILITY-MAP- } \\
\text { Master.dwg }\end{array}$ \\
\hline VALVE & Point & 1807 & $\begin{array}{l}\text { UTILITY-MAP- } \\
\text { Master.dwg }\end{array}$ \\
\hline VALVES & Point & 88 & $\begin{array}{l}\text { UTILITY-MAP- } \\
\text { Master.dwg }\end{array}$ \\
\hline MISSING & Point & 623 & $\begin{array}{l}\text { UTILITY-MAP- } \\
\text { Master.dwg }\end{array}$ \\
\hline FH & Point & 874 & $\begin{array}{l}\text { UTILITY-MAP- } \\
\text { Master.dwg }\end{array}$ \\
\hline X-TANK & $\begin{array}{l}\text { Point and } \\
\text { Polyline }\end{array}$ & 17 & $\begin{array}{l}\text { UTILITY-MAP- } \\
\text { Master.dwg }\end{array}$ \\
\hline X-WATER & Polyline & 5405 & $\begin{array}{l}\text { UTILITY-MAP- } \\
\text { Master.dwg }\end{array}$ \\
\hline WATER-SERVICE & Polyline & 5073 & $\begin{array}{l}\text { UTILITY-MAP- } \\
\text { Master.dwg }\end{array}$ \\
\hline MISSING & $\begin{array}{l}\text { Point and } \\
\text { Polyline }\end{array}$ & 2292 & $\begin{array}{l}\text { UTILITY-MAP- } \\
\text { Master.dwg }\end{array}$ \\
\hline CITY LIMITS & Polyline & 1 & $\begin{array}{l}\text { UTILITY-MAP- } \\
\text { Master.dwg }\end{array}$ \\
\hline
\end{tabular}

The client was using a user defined Oblique Mercator coordinate system for the CAD drawings, which was considered unusual, and the city wanted to use a more appropriate system, such as the State Plane coordinate system. Based on the parameters provided by the client, a projection file was created for the CAD data called the Elko_QQ projected coordinate system (see Figure 2-1). 


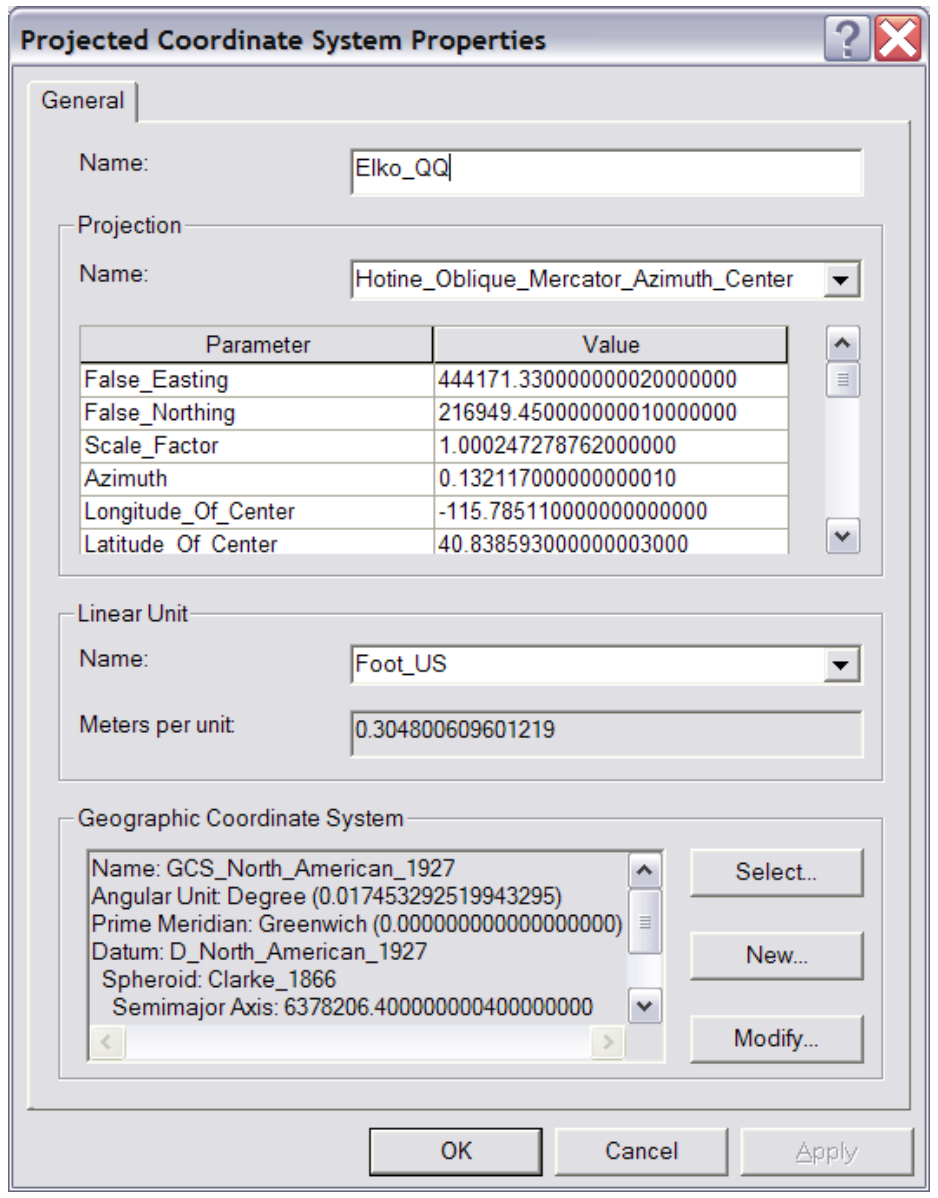

Figure 2-1. Coordinate system created for base AutoCAD data

To reference the CAD data with existing GIS reference data, the parcels dataset, the CAD data was assigned the Elko_QQ coordinate system using ArcCatalog. The projection file associated with the CAD file must be located in the same file folder and named the same as the CAD file with a .prj file extension. The data was added to ArcMap along with base reference data to determine how well the data overlaid with the GIS data layers. Once the client approved the spatial accuracy of the CAD data it was then ready to be converted into the GIS database.

The exported data layers from CAD were placed in an intermediate file geodatabase. The geodatabase had the Elko_QQ coordinate system applied, created for the CAD data. Since CAD layers can be "turned off", and are not viewable in ArcMap by default, an unexpected amount of information was created in the points, polylines, and polygons feature classes. Selective features, such as hydrants, mains, and service connections were then appended to the project geodatabase using a geoprocessing model built using ModelBuilder (see Figure 2-2). The geoprocessing tools available in ArcMap provide the ability to extract, re-project, and append files to the appropriate feature classes. The model created with ModelBuilder made the data conversion quick and easy for appending multiple data files to the geodatabase. 


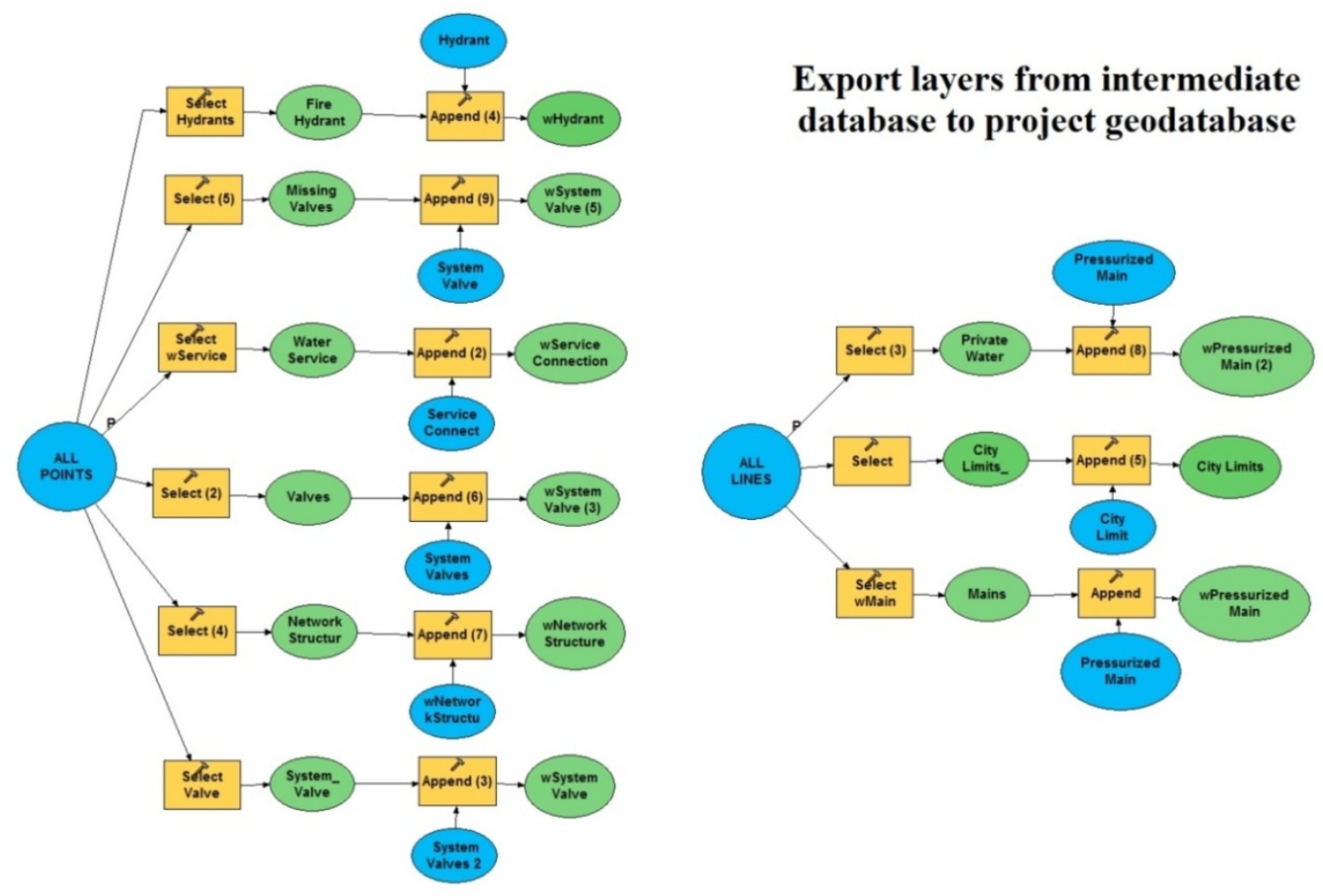

Figure 2-2. Geoprocessing model for extracting and appending data to geodatabase

Once the data was loaded into the geodatabase, features such as the city limits feature class needed to be turned into a closed polygon for the feature to append into the predefined polygon feature class. Also, the addition of any supplementary data from the CAD file was done manually in ArcMap using the object load data tool.

The shapefile data represented points of service connection. The data was reviewed and its attribute information held no pertinent records, so the data was used to update the geometry of the service connection feature class. To add the data to the geodatabase, the shapefile was appended to the service connection feature class as a meter subtype; the records are to be cross referenced with billing services by the client in order to apply the correct subtype (i.e., Flat Rate or Meter) and attribute information for each service connection.

Paper maps provided were scanned and saved as TIFF files by the client. The paper maps are as-built drawings with detailed information about the water utility network. The scanned maps were then georeferenced using the parcels data layer as the reference. The georeferencing toolbar allowed the raster files to be referenced in proper spatial coordinates; for more information see Appendix A. The use of the scanned maps provided a main source of information to populate attribute information of features during edit sessions in ArcMap. 
The scanned maps were hyperlinked to features in the water network. Initializing, maintaining, and accessing hyperlinks are further explained in Appendix B. The pressurized main feature stores a field with the path name of each scanned map. The hyperlink base is stored in the map document properties and the file name of the TIFF is stored in the pressurized mains attribute table. The hyperlink enables the user to select a main and retrieve the as-built plan associated to the original information used to create the features. To enable the hyperlink, the user must 1) select the hyperlink tool, 2) place the mouse over the water main, and 3) select the feature; the scanned image then opens up in Windows Picture and Fax Viewer, the default image viewer (see Figure 2-3).

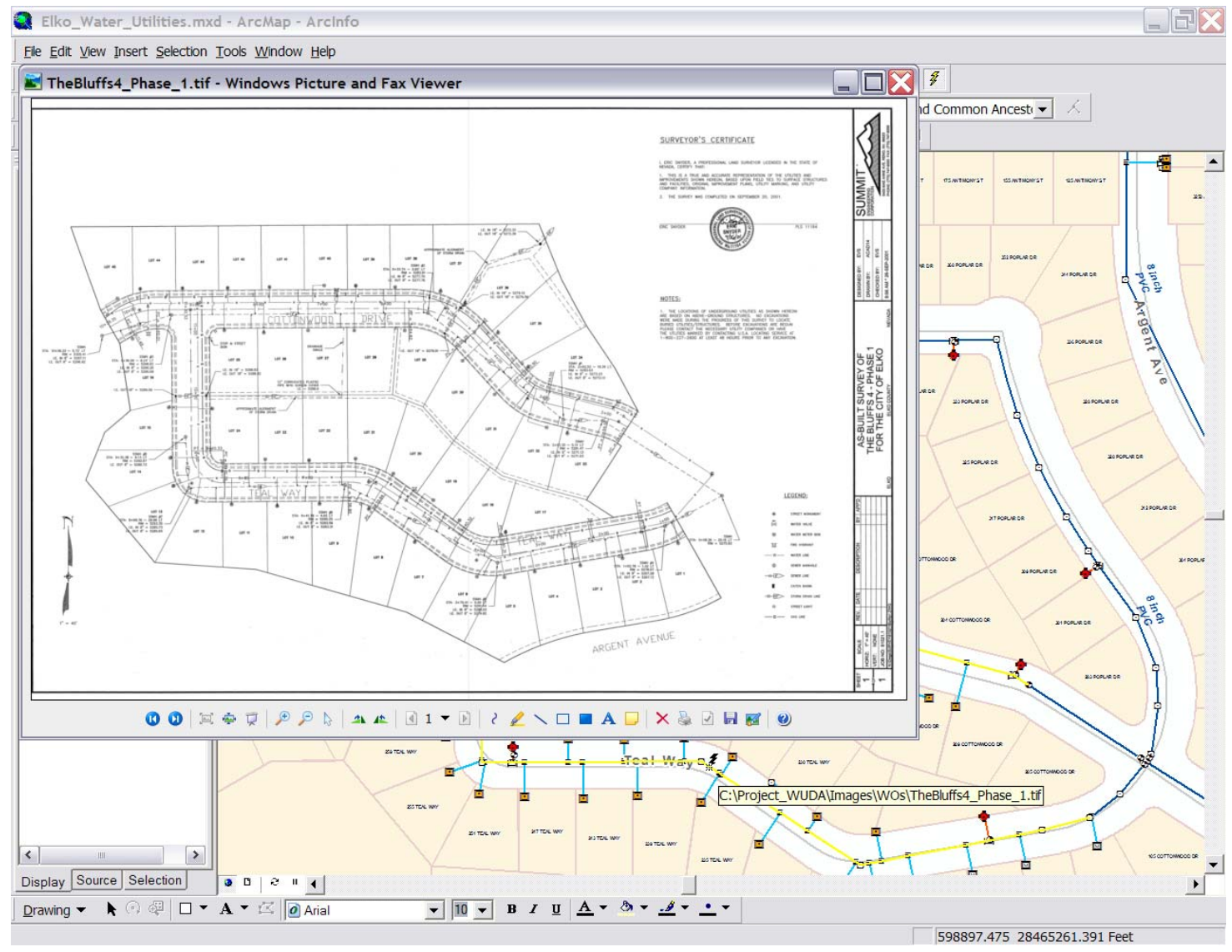

Figure 2-3. Hyperlink to an as-built document from selecting an active feature

The final data manipulation was to incorporate an Excel table into the geodatabase in ArcCatalog. A new database table was designed to store the detailed hydrant records. The Excel table was loaded into the database table using the Simple Data Loader in ArcCatalog. Once the data was loaded, a simple relationship class was created to relate the hydrant feature class and the hydrant table information using Hydrant_ID as the primary key and the FacilityID as the foreign key. The relationship class permits the hydrant feature class to be queried along with the associated hydrant table. 



\section{Software Design}

The software design for the project utilizes out-of-the-box ArcGIS 9.2. A custom .Mxd file, called Elko_Water_Utilities.mxd, was created based on the needs of the primary editor, the city's senior engineer. The following toolbars:

- Editor

- Geometric network editor

- Spatial adjustment

- Georeferencing

- Layout

- Advanced Editor

- Utility Network Analyst

are recommended to be placed in the map document of the main editor. These toolbars were selected because they are the tools most frequently used to edit features located in the geodatabase. The workstation, at the client's site, used for implementation of the geodatabase has an ArcInfo license which provides the appropriate license level for editing the geometric network. The network features can be created and edited in ArcInfo and ArcEditor but are read-only in ArcView. A geometric network projected on the fly cannot be edited within ArcMap (ESRI, 2008c).

The workflow of data pertaining to the water network should incorporate the following suggestions to see that the information is properly stored in the GIS. The Engineering Department receives data in CAD format or a hard copy map by an engineering firm. The paper maps need to be scanned, saved as a TIFF, and named based upon the project name. The scanned file will need to be added to a map document to be georeferenced so that data can be overlaid with other corresponding GIS data layers. The information from the maps can be extracted and entered into the geodatabase. Extracting information from AutoCAD into an ESRI feature classes permits the collection of data to be placed in the geodatabase to maintain an up-to-date database.

Incorporating data into the geodatabase allows the user to view and add additional information about the water network facilities. The files stored in the database make it easy for the client to refer to information on the network. Without the use of a GIS, the client would need to search through cabinets of paper maps or file folders for CAD files to locate needed information about the network facilities. It is estimated that storing information in GIS compared to previous techniques will save hours or even days of research for employees. It will allow the city employees to focus on the important problems that are being addressed.

The Elko County parcels dataset, provided by Elko County Engineering Department, and a 2006 one meter aerial imagery are reference data used to georeference scanned and $\mathrm{CAD}$ data files. Information submitted by engineering firms is collected by the Engineering Department at the city and placed into the geodatabase. Data received from field crews, such as service cards and personal feedback from staff need also to be collected and placed into the GIS database. The final product for the data compilation of 
the network provides hard-copy maps generated from the layout view in ArcMap which are distributed to the consumer.

The design of the system is intended to help ease the process of data input and maintenance. Figure 3-1 represents a use case scenario of the workflow procedures the client would undertake to preserve the maintenance and operations of the domestic water network facilities.

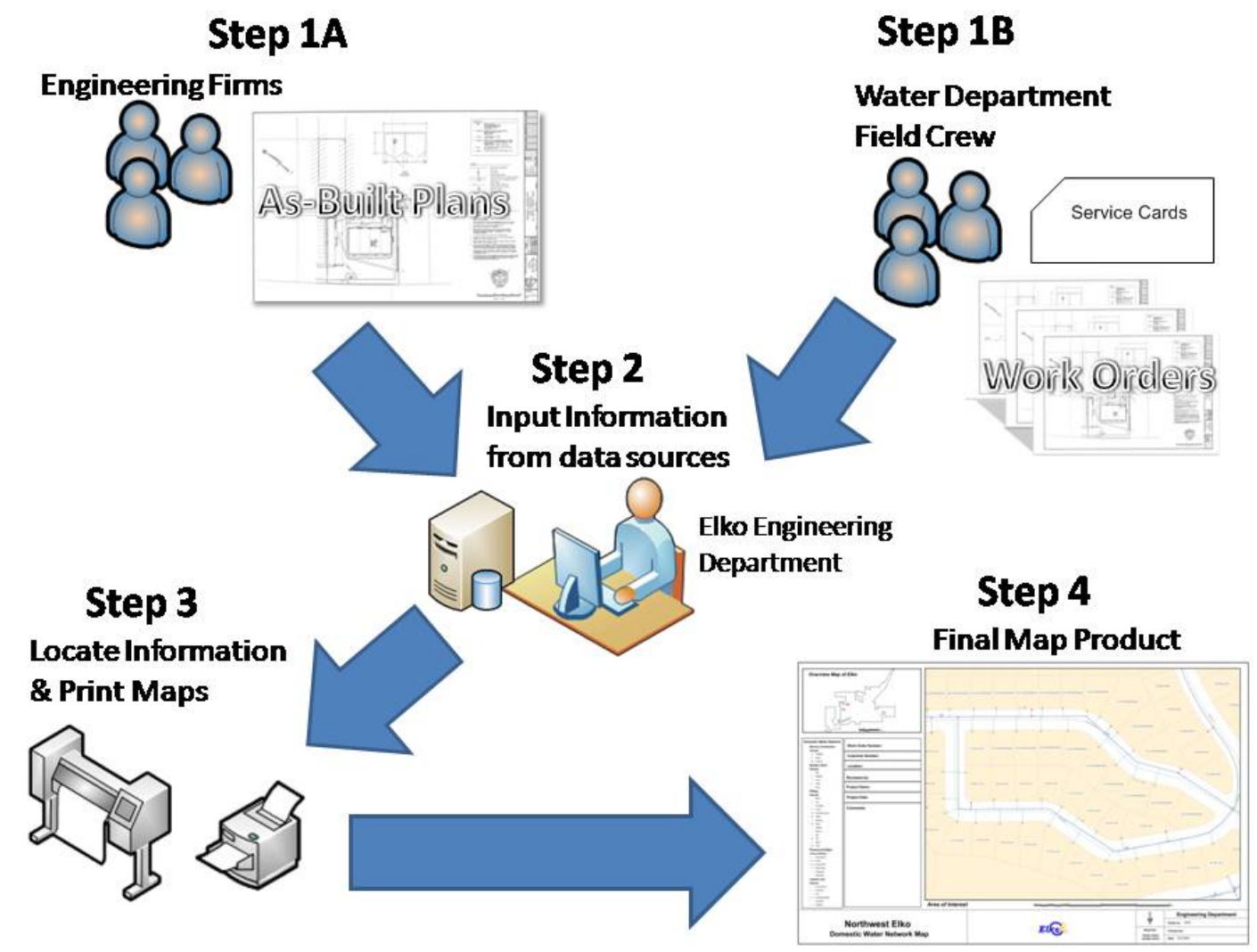

Figure 3-1. Work-flow procedure for maintaining the GIS

\subsection{System Architecture}

This project will make use of ArcGIS 9.2 to store and maintain geographic information for the domestic water utility network infrastructure for the EMWD. The system architecture is composed of four main levels: the input, processing, usage, and output of data (see Figure 3-2). The system architecture is based upon the assessment provided by the client. Each component described in the system architectural design has been implemented for use in this project. 


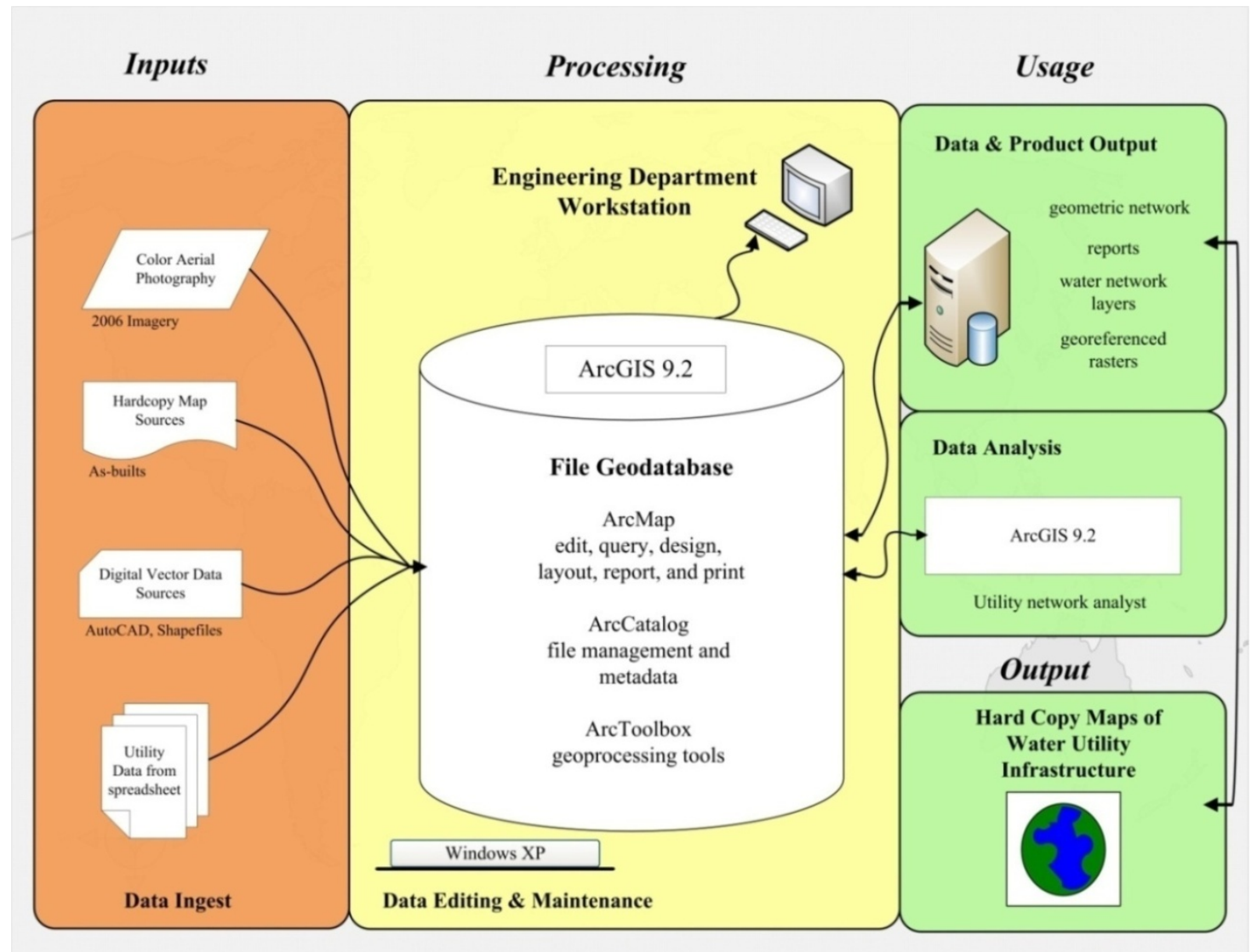

Figure 3-2. System architecture of the project

Upon implementation of the project, the client had a personal stand-alone workstation with an ArcInfo 9.2 license and a Windows XP professional platform installed on the machine. The workstation is the primary host of the file geodatabase. The data will reside on the local machine as the city's senior engineer will be the main editor of the GIS database. The workstation has the following minimum specifications as outlined by ESRI documentation for running ArcInfo 9.2 on a Windows 2000 Professional Platform:

Hardware Requirements

CPU Speed:

1.6 GHz recommended or higher

Processor:

Intel Core Duo, Intel Pentium or Intel Xeon Processors

Memory/RAM:

1 GB minimum, 2 GB recommended or higher

Display Properties:

Greater than 256 color depth

Screen Resolution:

1024 x 768 recommended or higher at Normal size (96dpi)

Disk Space:

1.2 GB 
The inputs for the project entail the use of data from various sources, such as digital vector data and Excel spreadsheets. The data has been placed into an ESRI file geodatabase via feature classes and a database table. After the data conversion process, the tools needed to create, update and maintain the water network structure, such as creating, splitting, and merging of features are included in the out-of-the-box ArcGIS 9.2 suite. ArcCatalog will be used primarily for file management processes and for making updates to the metadata files. ArcToolbox will be utilized to perform geoprocessing events. Geoprocessing in ArcGIS allows the user to conduct analysis, statistics, and data manipulation which are very useful when placed in a model using ModelBuilder. Once data has been analyzed it is then plausible to extract reports and statistical analysis. The final output product is to provide detailed hard-copy maps of the water network 


\section{Geodatabase}

A file geodatabase was created to store the data files in a central repository for easy access and maintenance of data files. The geodatabase contains a geometric network that must be utilized with an ArcInfo license level for editing capabilities.

\subsection{Database Design}

The database design for this project is based on the water utilities data model available from the ESRI website. Industry specific data models are meant to simplify the process of implementing projects and to help promote industry standards to ArcGIS users. The data models provide an excellent starting point in project implementation that can be modified in ArcCatalog. The water utilities data model was utilized for this project and was modified to fit the client's use specifications using ArcCatalog. Figure 4-1is a thumbnail of the complete updated data model that can be located on the MIP data disc in the DatabaseDesign folder. A generalized view of the project database (see Figure 4-2) provides an outline for the final geodatabase and the content that it includes. The outline serves as a resource for deciphering the content placed in the complete data model. The data model was created with the use of an ESRI ArcScript sample application called Geodatabase Diagrammer. The application has an extension that operates from within ArcCatalog that scans a geodatabase and creates a Visio diagram with visual elements to generate a data model diagram. 


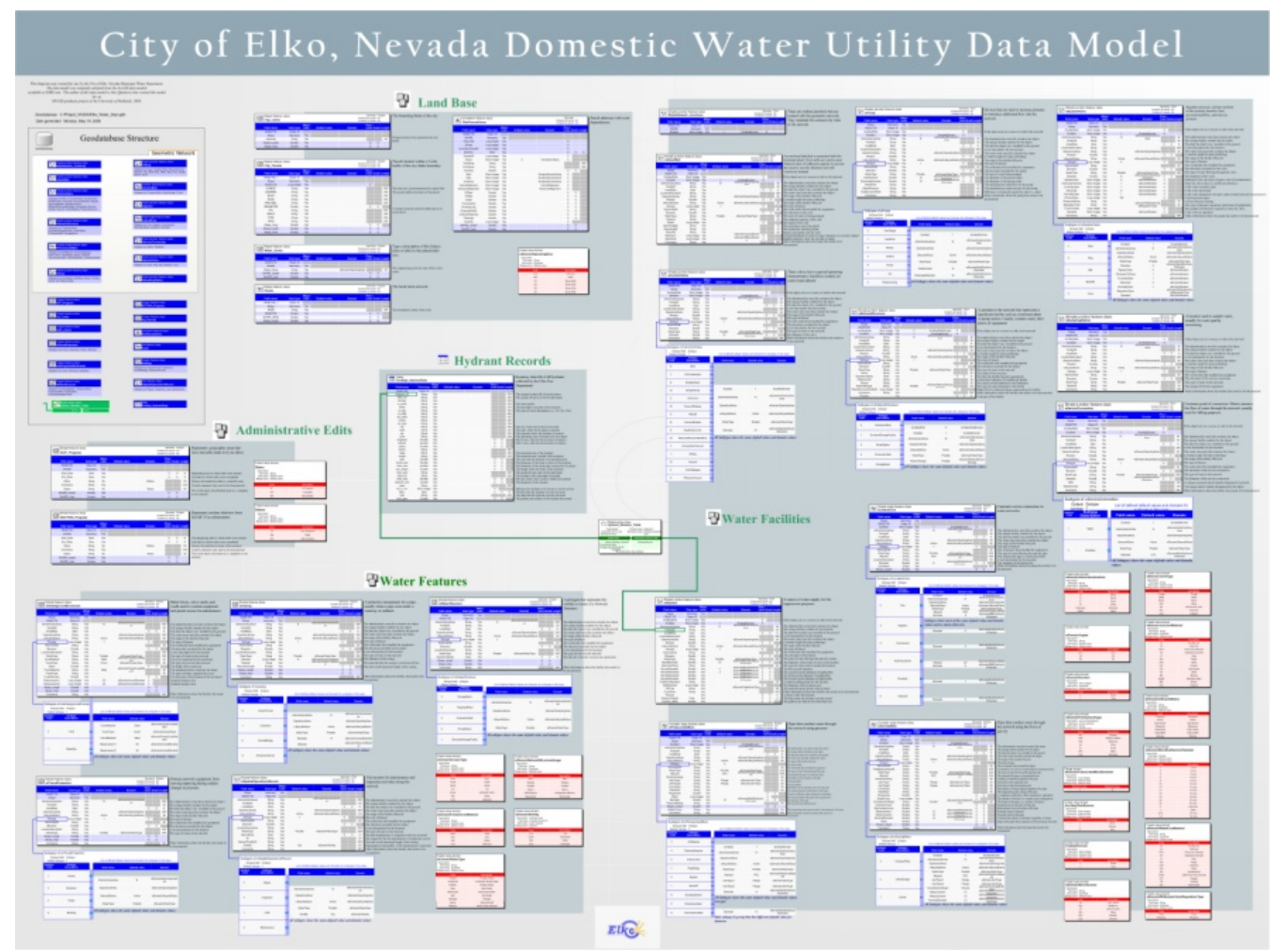

Figure 4-1. Complete detailed version of water utility data model

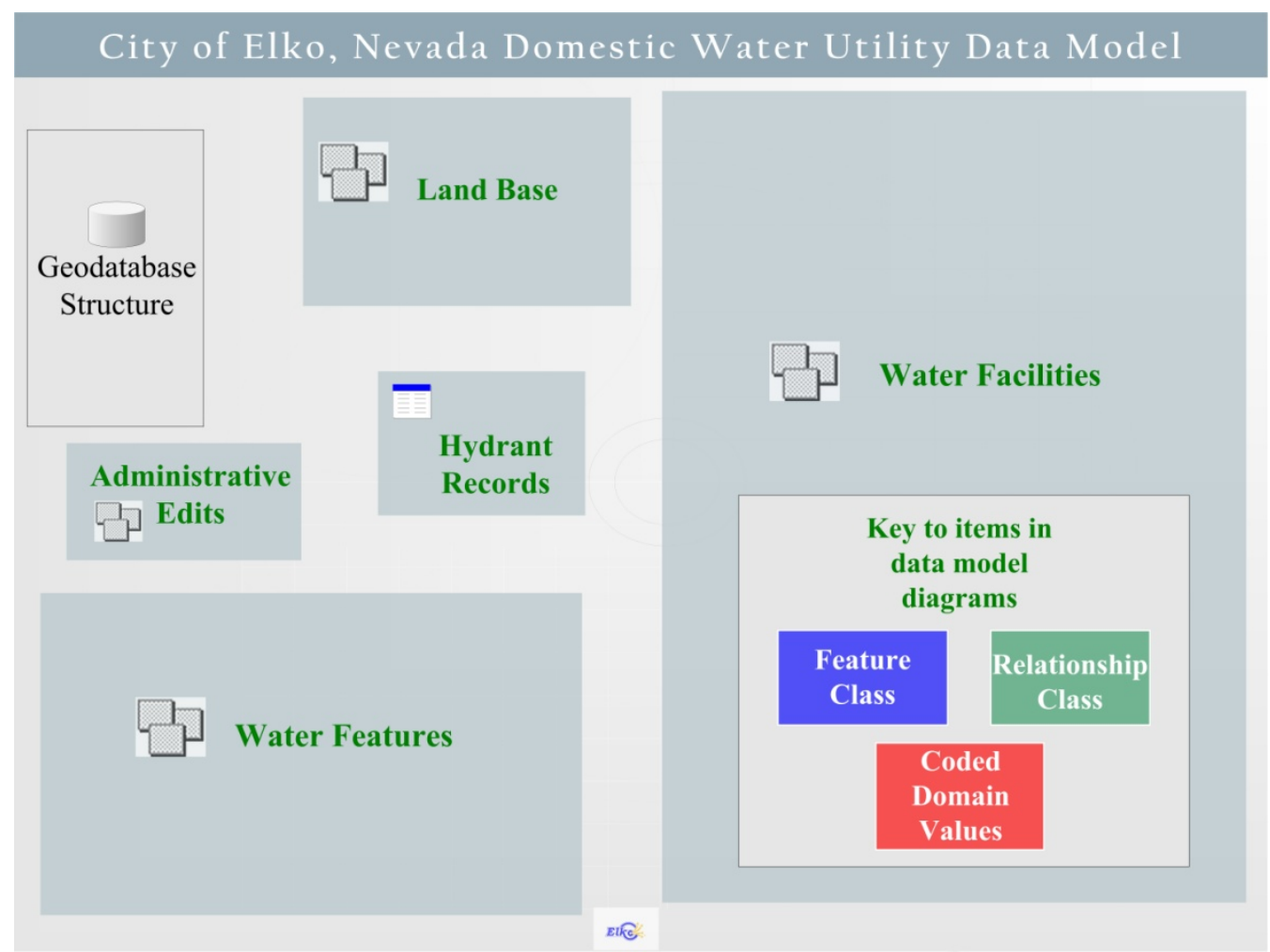

Figure 4-2. Generalized geodatabase of the water utility data model 
The two feature datasets added to the existing data model are named ADMIN_EDITS and Landbase_Data. The names of the two feature datasets were shortened in the geodatabase and a descriptive name is provided in the database diagram model. The additional feature datasets include feature classes that store spatial maintenance and reference data. The ADMIN_EDITS is used to document geographical locations of changes made to the drawing files. There are two different feature classes in the dataset: EDIT_Progress and SECTION_Progress. The EDIT_Progress feature class is intended to track and record changes by defining a location specified by user. Attribute fields are designated to track dates and the editor responsible for making changes in the drawing (see Figure 4-3).

\begin{tabular}{|c|c|c|c|c|c|c|c|}
\hline \multicolumn{4}{|c|}{$\begin{array}{ll}\text { Simple feature class } \\
\text { EDIT_Progress }\end{array}$} & \multicolumn{4}{|c|}{$\begin{array}{l}\text { Geometry Polygon } \\
\text { Contains M values No } \\
\text { Contains } Z \text { values No }\end{array}$} \\
\hline Field name & Data type & $\begin{array}{l}\text { Allow } \\
\text { nulls }\end{array}$ & Default value & Domain & $\begin{array}{l}\text { Prec- } \\
\text { ision }\end{array}$ & Scale & Length \\
\hline OBJECTID & Object ID & & & & & & \\
\hline SHAPE & Geometry & Yes & & & & & \\
\hline Start_Date & Date & Yes & & & 0 & 0 & 8 \\
\hline End_Date & Date & Yes & & & 0 & 0 & 8 \\
\hline Editor & String & No & & Editors & & & 50 \\
\hline Comments & String & Yes & & & & & 100 \\
\hline Status & String & No & & Status & & & 50 \\
\hline SHAPE_Length & Double & Yes & & & 0 & 0 & \\
\hline SHAPE_Area & Double & Yes & & & 0 & 0 & \\
\hline
\end{tabular}

Figure 4-3. The Edit Progress feature class

The SECTION_Progress feature class is used to track changes in the network by sections. The section polygons are outlines that were adopted from the public land survey sections. The documentation of changes by section will serve as a way to track and record the history of edits made during edit sessions on the network in a grid system. The two feature classes share the same coded domain values that record the editor and the lifecycle status of the progress polygons (see Figure 4-4 and Figure 4-5)

\begin{tabular}{|cc|}
\hline \multicolumn{2}{|l|}{ Coded value domain } \\
Editors \\
Description \\
Field type String \\
Split policy Default value \\
Merge policy Default value \\
\hline Code & \\
\hline AQ & Description \\
TF & Alex Quintero \\
Other & Tony Ferguson \\
\hline
\end{tabular}

Figure 4-4. Valid entries of editors

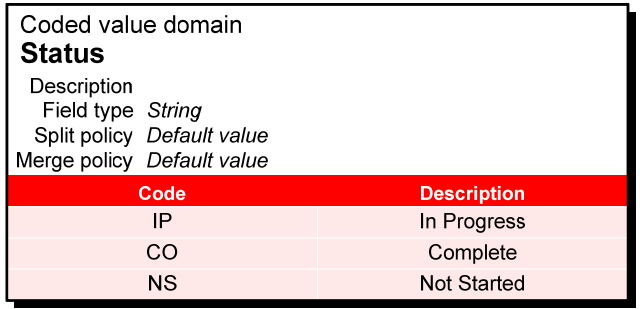

Figure 4-5. Valid entries of progress status

The Landbase_Data dataset includes four feature classes: the Elko roads, parcels, city limits and water zones. The road and parcel feature classes are used primarily for reference purposes. The roads layer is updated by the Street Department and includes street name information for each of the street centerlines (see Figure 4-6). 


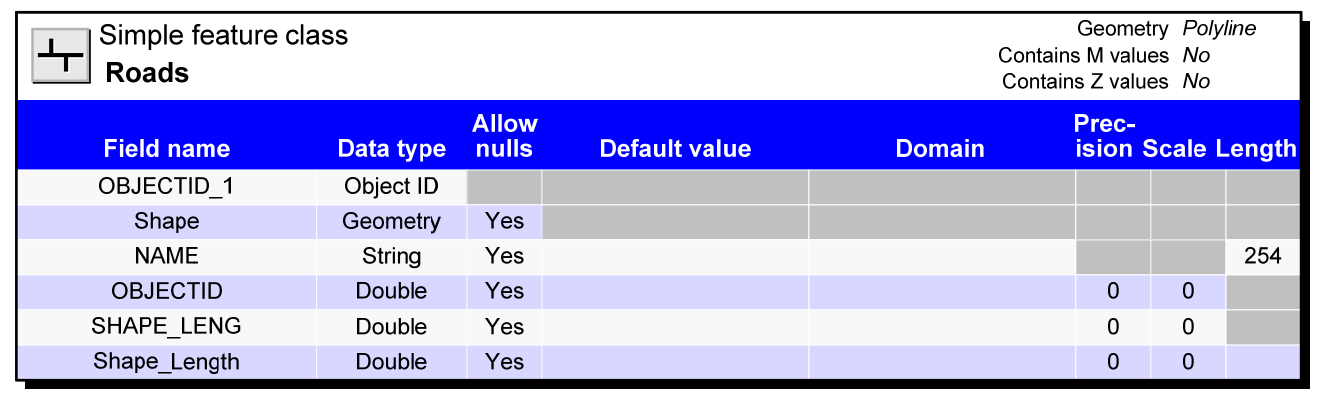

Figure 4-6. The road feature class

The parcels data is updated on a continual basis by the Elko County Engineering Department. They provide the city with parcel updates on a monthly basis that contain attribute information for each parcel record in the feature class (Figure 4-7).

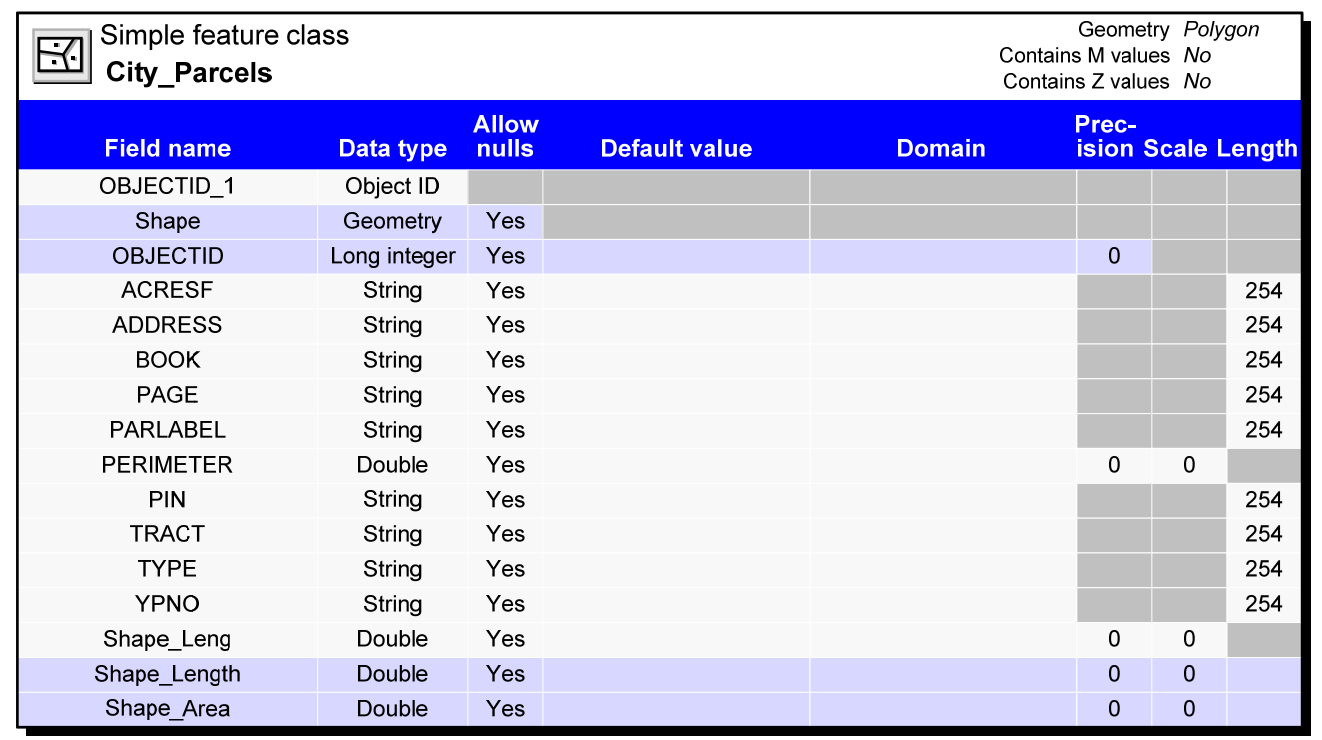

Figure 4-7. The city parcels feature class

The parcels are used as reference data and also to extract data from the file, such as address and Assessor Parcel Number (APN). The data is used to update service connection fields, location description and APN, to identify parcels with service connections, discussed further in section 7.1.2. The city limits feature class identifies the City of Elko's political boundary, which is used as reference data source (see Figure 4-8). 


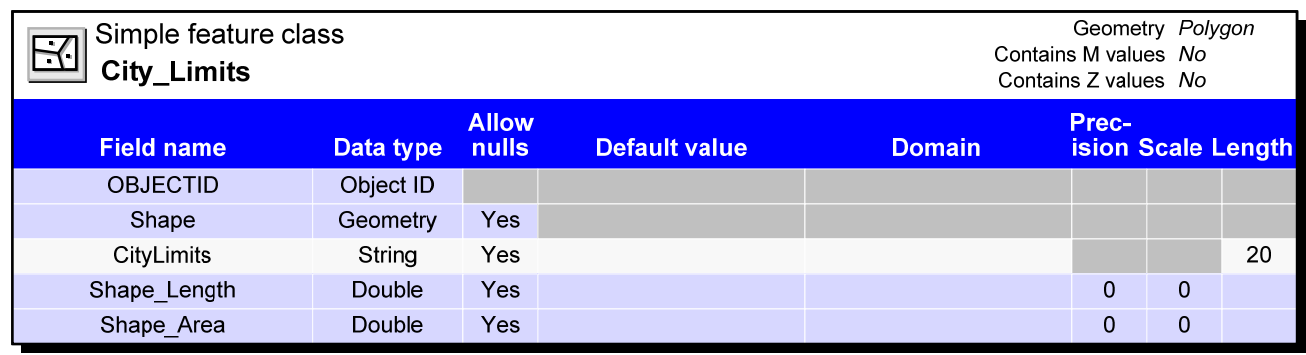

Figure 4-8. The city limits feature class

The water zones identify geographic locations of predefined pressurized water zones.

The water zones are used to update the water network features located within each of the geographic zone boundaries. Each water zone is identified by its specific zone code (see Figure 4-9). The coded domain values created for the pressure water zones contain a list of six valid values (see Figure 4-10). The water zone's coded domain values are incorporated into each of the network water facilities features to identify the feature and its location to each pressurized water zone region.

\begin{tabular}{|c|c|c|c|c|c|c|c|}
\hline \multicolumn{4}{|c|}{$\begin{array}{ll}\text { Simple feature class } \\
\text { Water_Zones }\end{array}$} & \multicolumn{4}{|c|}{$\begin{aligned} \text { Geometry Polygon } \\
\text { Contains M values No } \\
\text { Contains } Z \text { values No }\end{aligned}$} \\
\hline Field name & Data type & $\begin{array}{l}\text { Allow } \\
\text { nulls }\end{array}$ & Default value & Domain & $\begin{array}{l}\text { Prec- } \\
\text { ision }\end{array}$ & & Length \\
\hline OBJECTID & Object ID & & & & & & \\
\hline SHAPE & Geometry & Yes & & & & & \\
\hline Water_Zones & String & Yes & & wDomainOperatingArea & & & 50 \\
\hline SHAPE_Length & Double & Yes & & & 0 & 0 & \\
\hline SHAPE_Area & Double & Yes & & & 0 & 0 & \\
\hline
\end{tabular}

Figure 4-9. The pressure water zones features class

\begin{tabular}{|c|}
\hline Coded value domain \\
wDomainOperatingArea \\
Description \\
$\begin{array}{r}\text { Field type String } \\
\text { Split policy }\end{array}$ Duplicate \\
Merge policy Default value \\
\hline Code \\
\hline Unk \\
Oth \\
Z1 \\
Z2 \\
Z3 \\
Z4 \\
\hline
\end{tabular}

Figure 4-10. Valid values of pressurized water zones

Additional data added to the data model is a hydrant table and a relationship class (see Figure 4-11 and 4-12). 


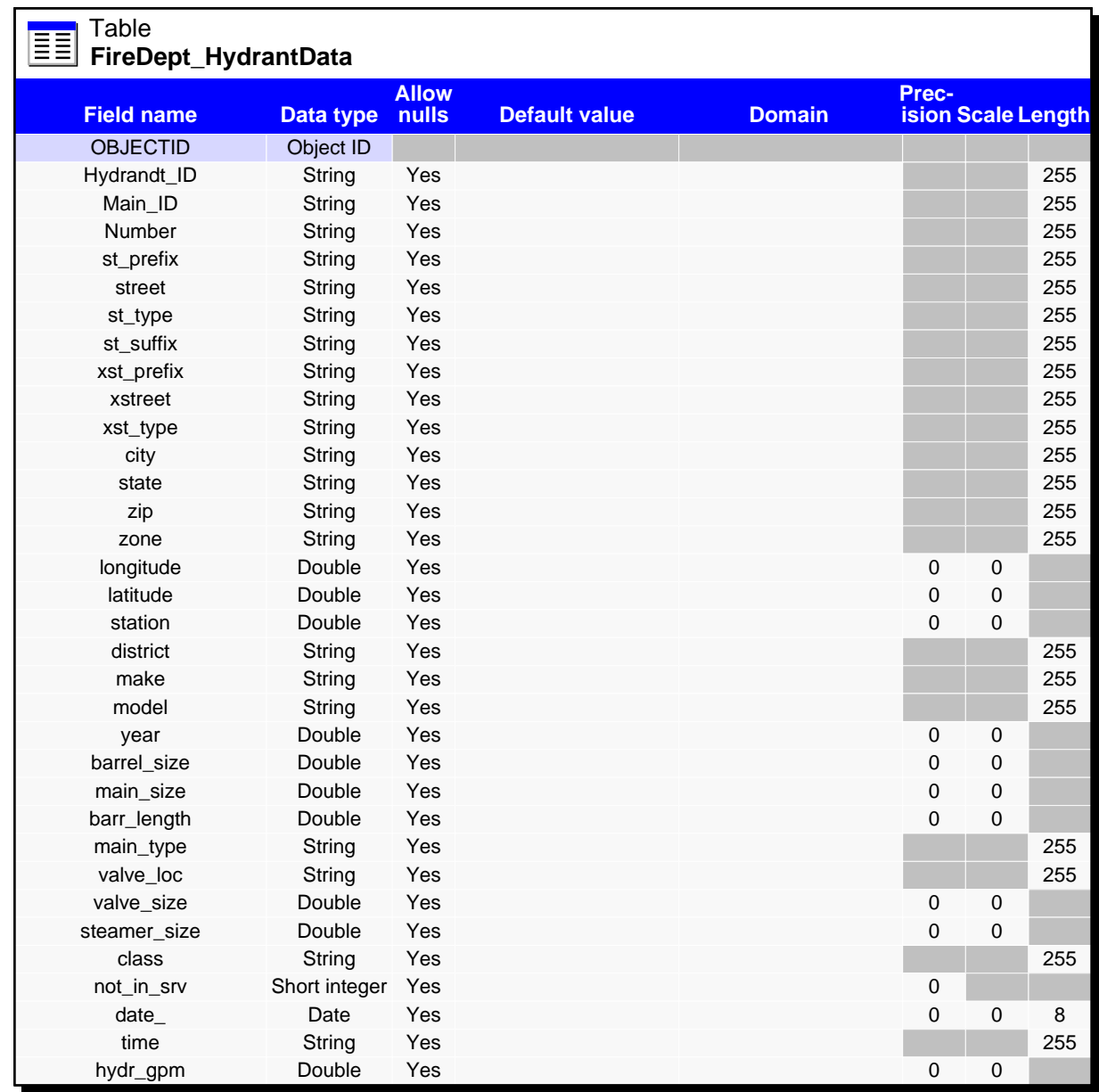

Figure 4-11. Hydrant data source table

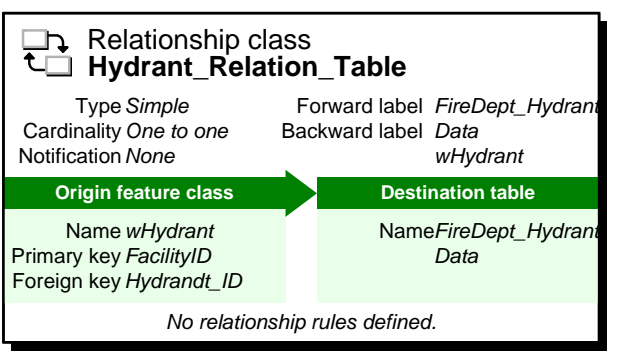

Figure 4-12. Hydrant relationship description

The relationship class provides a dynamic link between the hydrant table and the hydrant feature class. The table and the feature class are related by the primary and foreign key. The primary key is the Facility ID field in the hydrant feature class and the foreign key is the Hydrant ID field in the hydrant data table. The hydrant data table was provided by the Elko Fire Department and is useful for updating the hydrant information in the geodatabase. The hydrant table contains a large collection of data for hydrants located in the city which is cross referenced with the Fire Hydrant CAD map to populate the associated hydrant feature class with attribute information. 
The addition of a raster field was added to the hydrants feature class to add software functionality to the hydrant feature class. In the attribute table of the hydrant features is a raster field named Pictures. With a raster field, the user can choose a photo to upload to a picture file. The raster image is opened within ArcMap which can then be zoomed in and out, printed, saved as a JPEG or BMP file as shown in Figure 4-13.

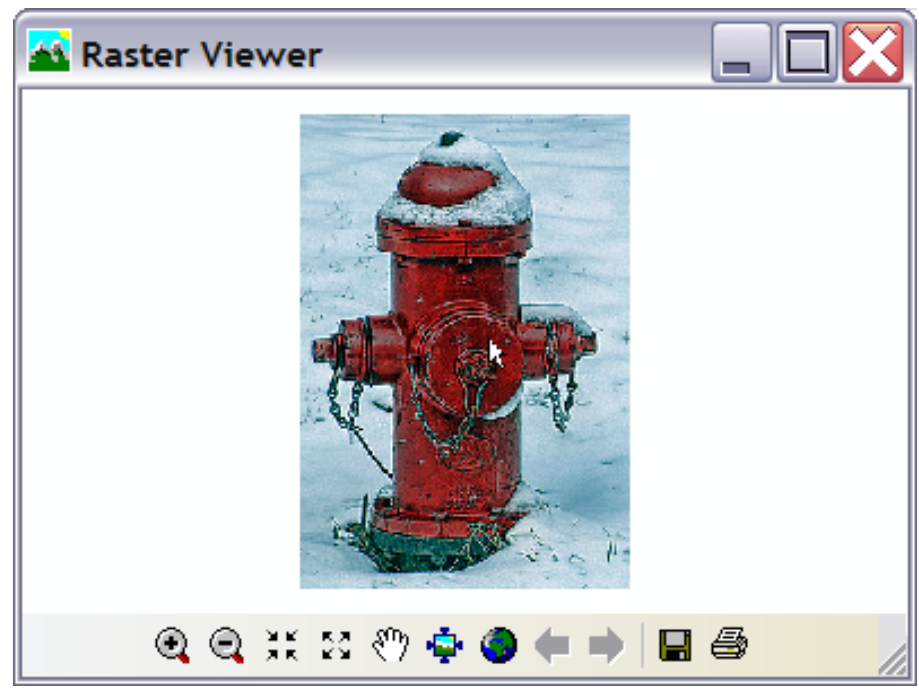

Figure 4-13. Photo uploaded in raster field of hydrant feature

The feature classes that reside in the Water Features and Water Network dataset are features that represent the physical water distribution system. The Water_Features feature dataset has five feature classes that document the water network facilities and maintenance operations. These feature classes are not part of the Water_Network dataset because the features are not part of the geometric network (see Figure 4-14).

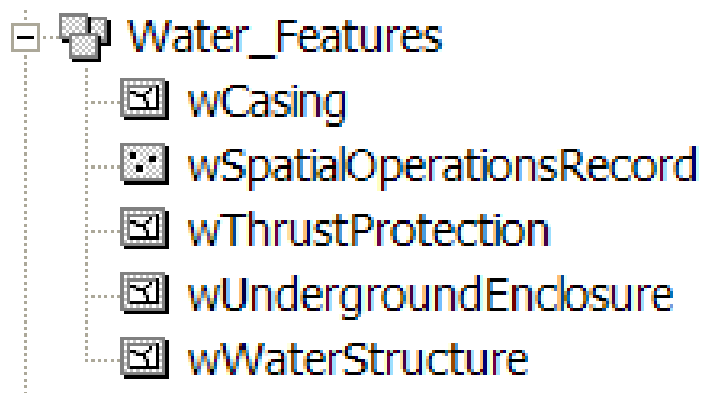

Figure 4-14. Water features dataset and feature classes

Although the features are part of the water network their role in the network does not follow the same rules as do the features placed in the Water Network dataset. For example, the spatial operations record feature class documents maintenance records of 
repairs, leaks and inspections that do not need to connect or follow connection rules in the network.

The feature classes located in the water network dataset are a collection network feature types - simple junction, complex junction, simple edge, and a complex edge featurethat participate in the geometric network (see Figure 4-15).

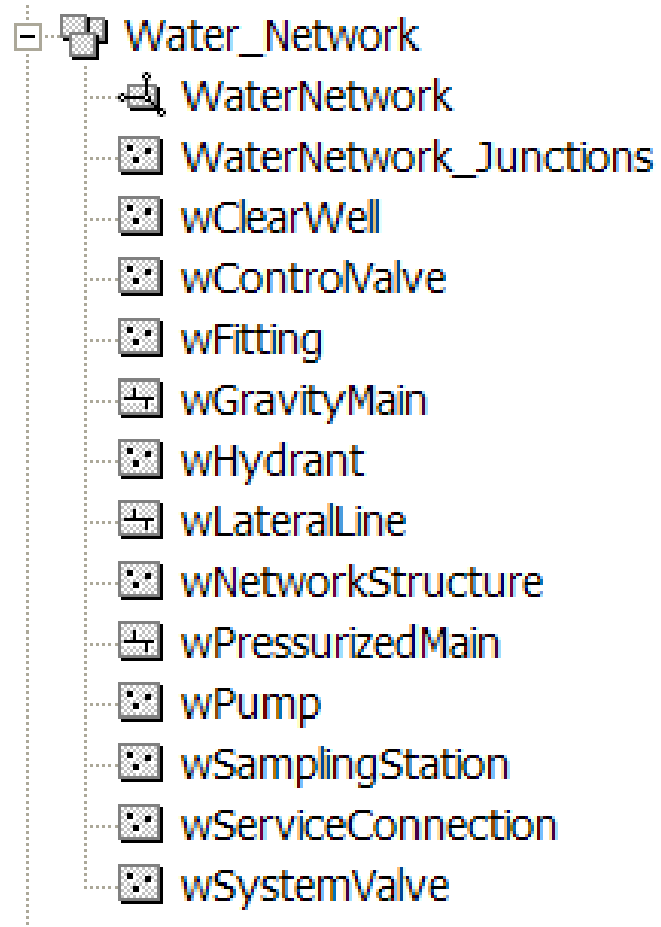

Figure 4-15. Water Network dataset, feature classes, and the geometric network

The data in the geometric network is comprised of edges, and junctions. A geometric network is composed of two types of edges, simple and complex edges. Simple edges are always connected to two junctions and will always break at a junction. A simple edge is used in this project for the lateral lines. Complex edges must connect to at least two junctions at their endpoints but they can be connected to additional junctions along their edge and not break. The use of complex edges is utilized in this project for gravity and pressurized mains.

\subsection{Network Connectivity Rules}

There are two types of connectivity rules - edge-junction and edge-edge rules - that can be associated to network features involved in a geometric network. The edge-junction rule specifies the valid types of junctions that may connect to an edge and the number of each type that can be connected. The edge-edge rule specifies the junction to be created based on the types of edges connected. The advantage of using the edge-edge rule is that it creates the appropriate junction when creating a new edge snapped to an existing edge feature. The connectivity rules can be established between two features classes, a feature class and the subtype of another feature class, or between a subtype of one feature and the 
subtype of another (ESRI, 2008c). Setting the network connectivity rules can be done from ArcCatalog or with the use of Geometric Network Editor tool. The rules for the network were set using the tools in ArcCatalog and the use of the geometric network connectivity rule editor were used to graphically display the rules applied to the edges and junctions (see Figure 4-16).

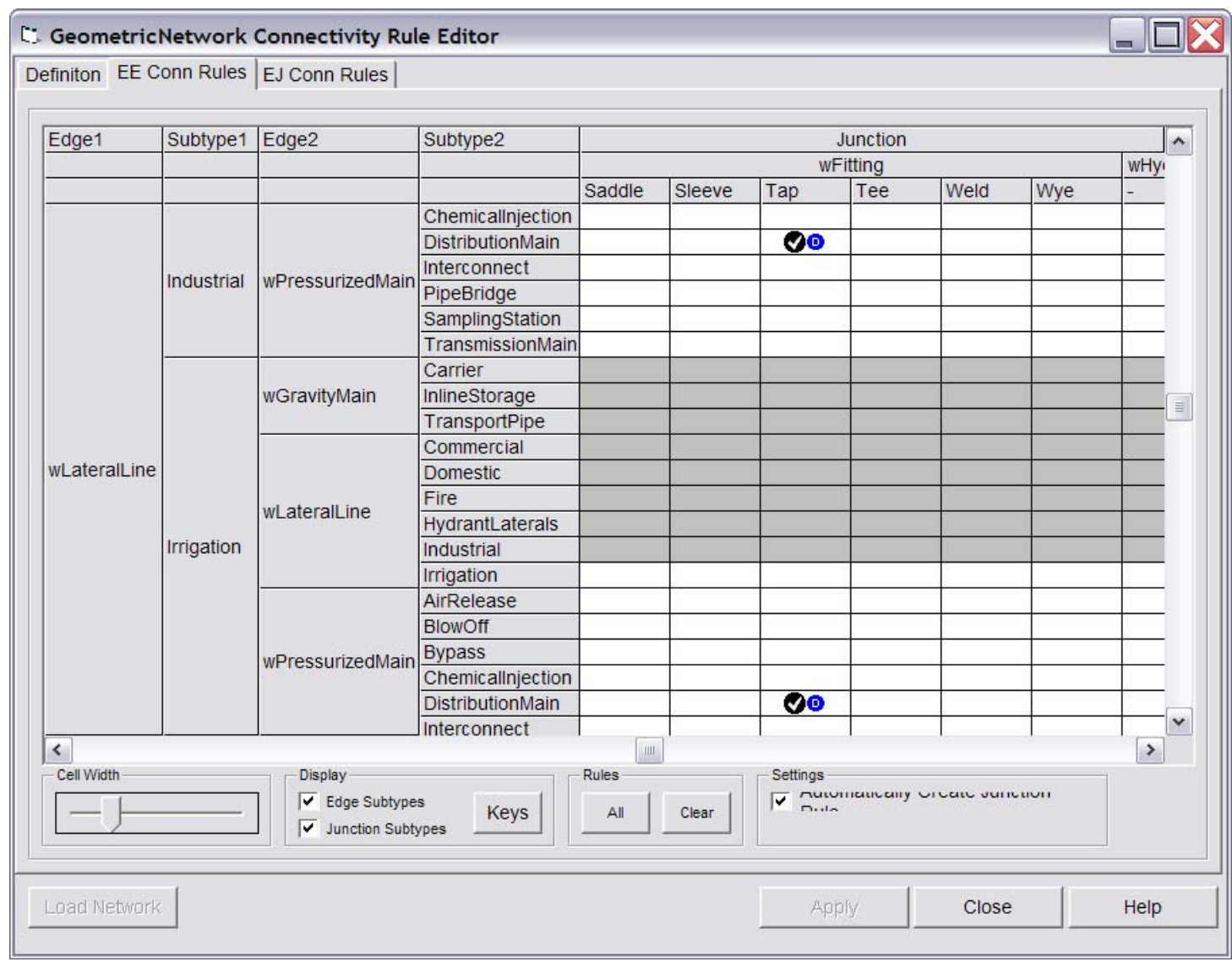

Figure 4-16. Example of edge-edge rules applied to network

The network connectivity rules are established to make editing the network less tedious. For example, when there is an installment of a fire hydrant assembly the editor needs only draw the hydrant lateral from the main line to the location of the hydrant. A tee fitting will be created based on the edge-edge rule applied to the network features. The network rules reduce the amount of time and error that may be introduced during an edit session. 



\section{Methodology}

\subsection{Performing Trace Analysis on Network}

The geodatabase encompasses the use of a geometric network for the water network features. The geometric network is composed of connected edges and junctions, along with connectivity rules that represent and model the water network (ESRI, 2008c). A geometric network is used to represent and model the real world water network and support the use of network tracing and analysis (Zeiler, 2004). The use of a geometric network has been implemented to execute trace analysis functions available from the Utility Network Analyst toolbar. The network traces were all executed in the same subdivision located in Northwest Elko. An overview map of the area is provided in Figure 5-1 and a subset of the network features present in the area are identified.

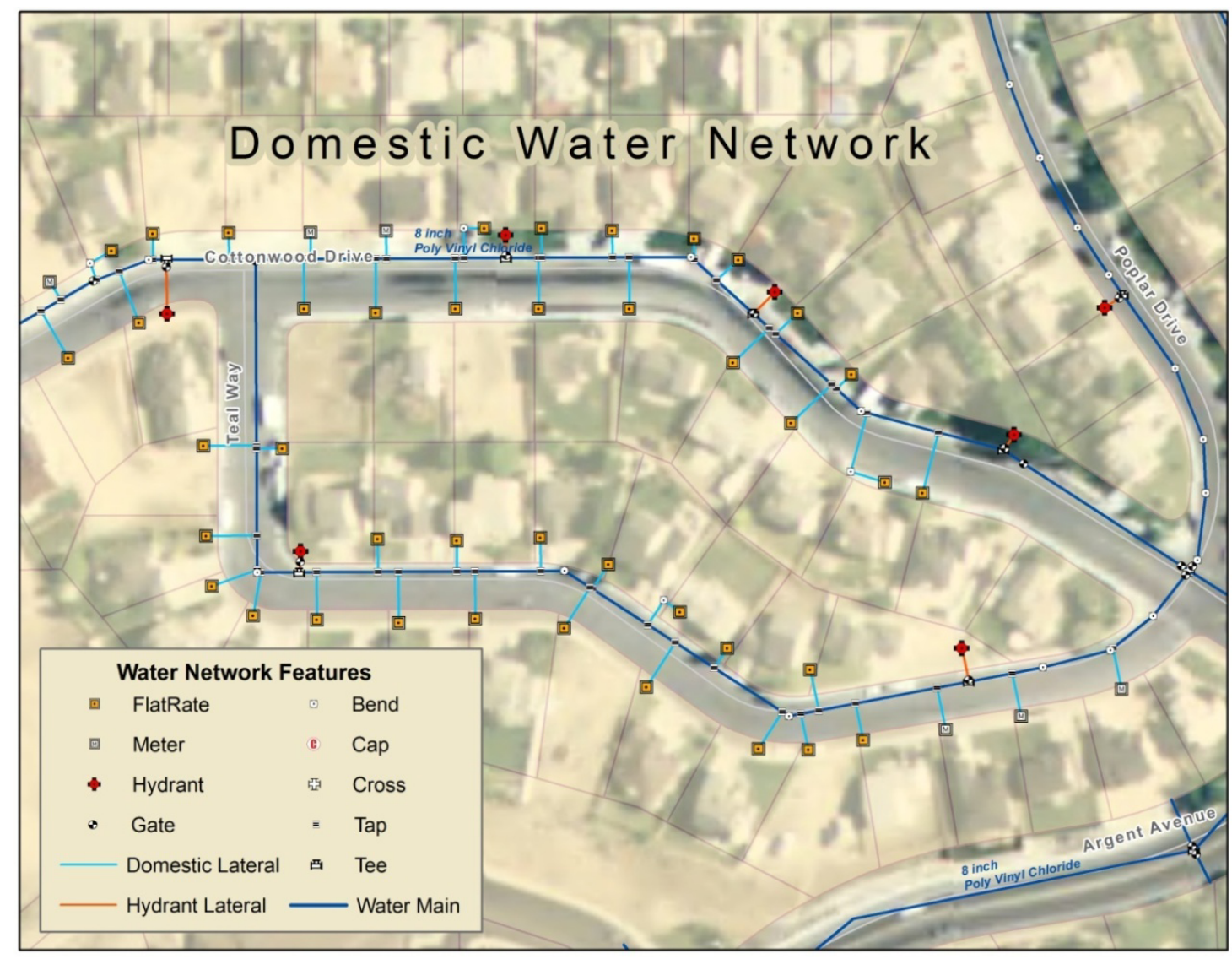

Figure 5-1. Location where network traces were executed

\subsection{Trace Analysis Operations}

The following list provides the trace task operations available in ArcMap for the domestic water utility, available through the Utility Network Analyst toolbar:

- Find connected 
- Find disconnected

- Find a path

Although, there are more trace tasks available in the Utility Analyst toolbar it is not recommended to be used by the client for this project. The other trace tasks available are designed for use in non-pressurized water systems or other networks, such as sewer and storm drain networks (Maneva, 2004).

\subsection{Tracing for Connected Features}

The find connected trace task supports the ability to check connectivity between features in the network as it allows the user to analyze features that are connected to one another.

The following is a set of instructions to perform the analysis:

1. Open the Network Analyst toolbar

2. Place a flag on a point of interest

3. Choose the Find connected task

4. Select Solve

The results of the analysis will highlight all the water network features in red that are connected to the point of interest, the flag (see Figure 5-2).

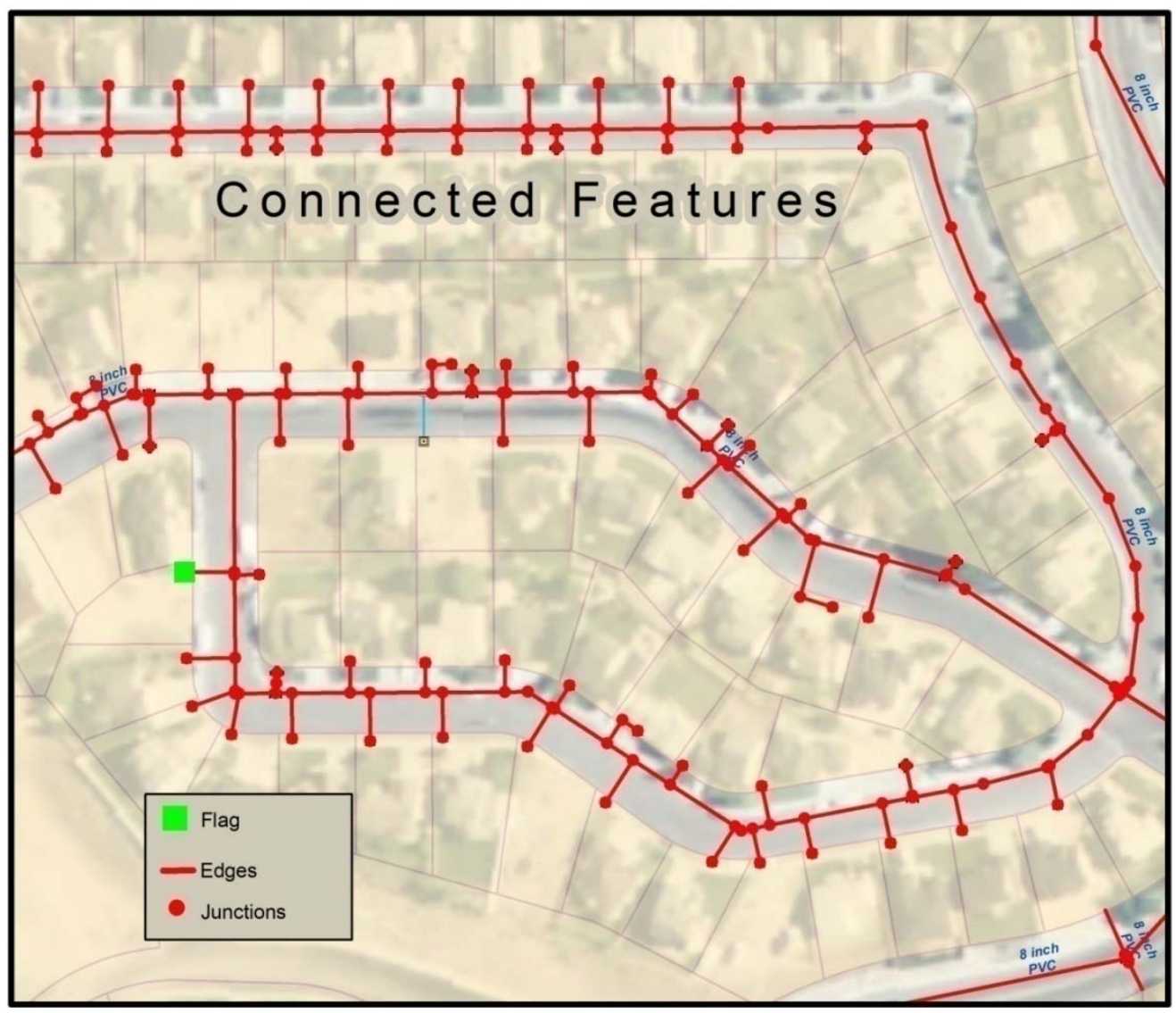

Figure 5-2. Results of trace task to find connected features 


\subsection{Tracing for Disconnected Features}

The find disconnected trace task supports the ability to check for breaks in the connectivity of features in the network. For example, if a service lateral is not snapped to the edge of a main, the find disconnect trace will identify the lateral and any other feature connected to it. The following is a set of instructions to perform the analysis:

1. Open the Network Analyst toolbar

2. Place a flag on a point of interest

3. Choose the Find disconnected task

4. Select Solve

The results of the analysis will highlight all the water network features in red that are disconnected to the point of interest (see Figure 5-3).

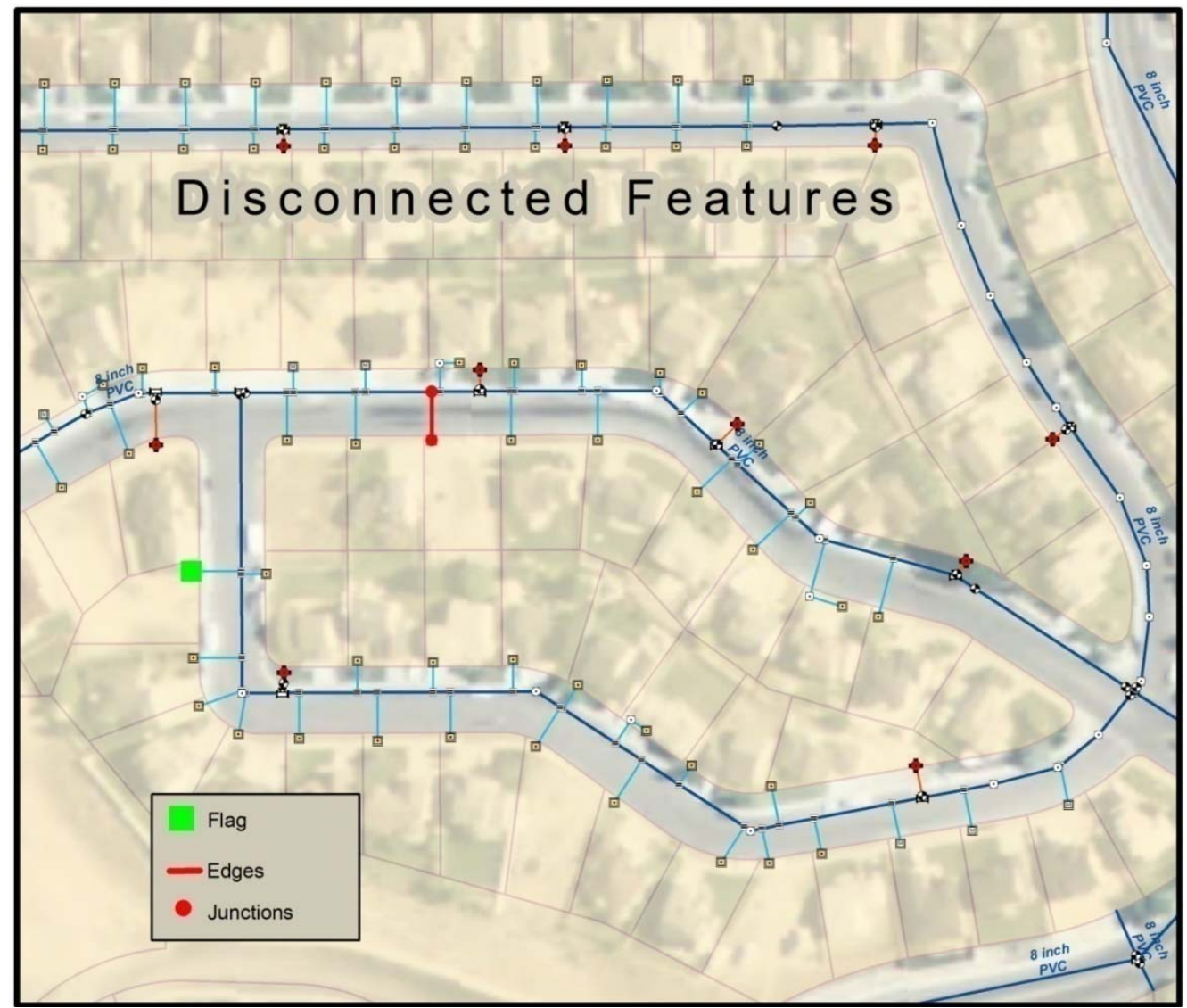

Figure 5-3. Results of trace task to find disconnected features

\subsection{Tracing a Path}

The find trace path task supports the ability to find the path between two points in the network. The task analyzes the availability of water to provide a service for a customer (see Figure 5-4). The analysis is useful in determining if a new water service can be provided in the network based on the location of the point of water source and potential customer site. The following is a set of instructions to perform the analysis: 
1. Open the Network Analyst toolbar

2. Place a flag on a point of water source

3. Place a flag on new potential customer

4. Choose the Find path task

5. Select Solve

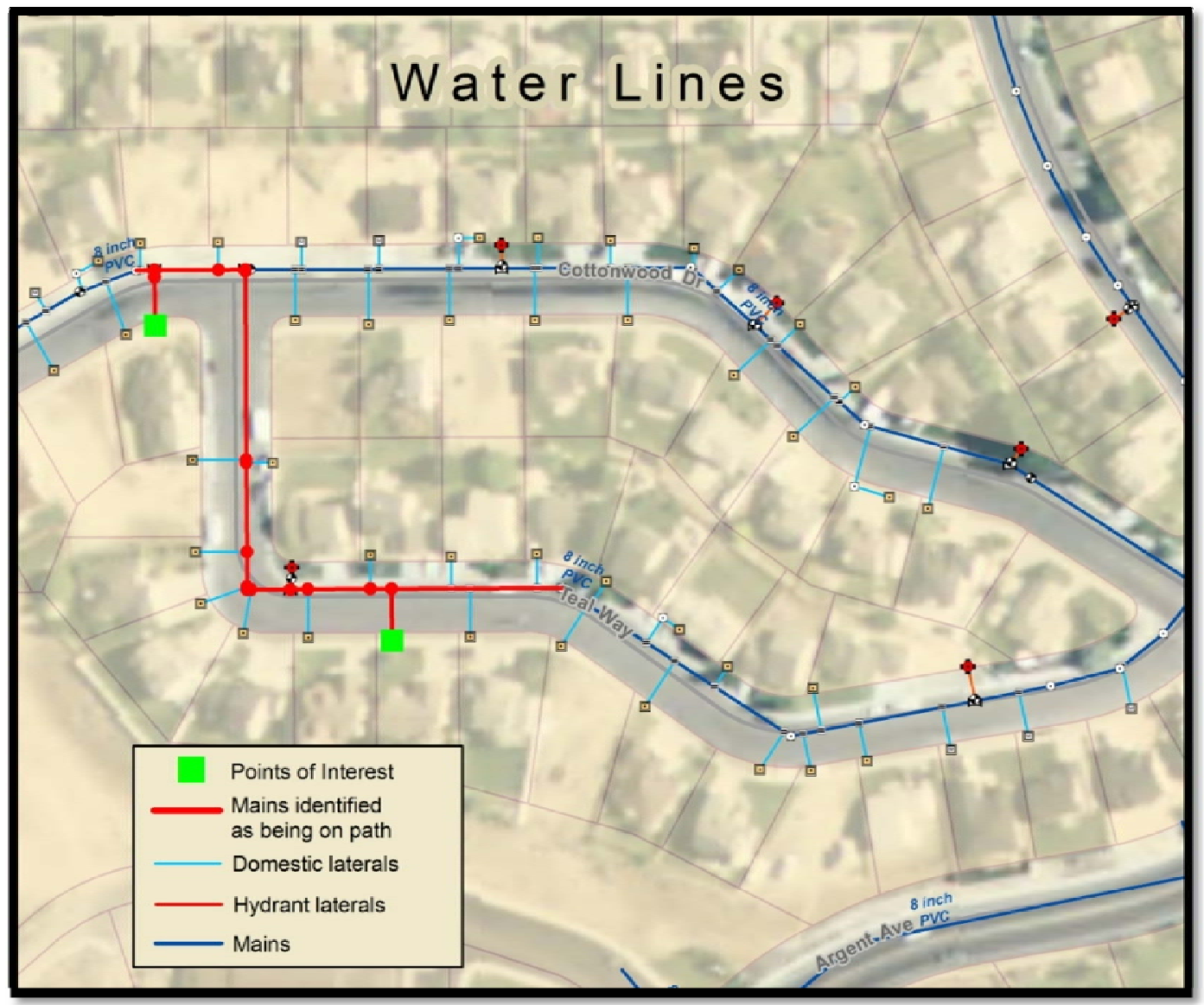

Figure 5-4. Results of trace task to find the path from two points

\subsection{Valve Isolation Trace}

Another trace task that can be applied to the water network utilizing the Find connected task includes isolating a point on the network. Isolating a point on the network is used to identify the valves that need to be closed to repair a leak in the main. The editor places a flag on the reported location of a water leak; once the flag is placed on the feature, which identifies the location of a water leak, the results can be solved and graphically displayed on-screen (see Figure 5-5). The following is a set of instructions to perform the analysis:

1. Place an edge flag at reported site of water leak

2. Disable system valve layer

3. Navigate to the analysis options menu. In the results tab chose Selection. In results content choose the features stopping the trace.

4. Select the system valves to be only selectable layer 
5. Choose the Find connected task

6. Select Solve

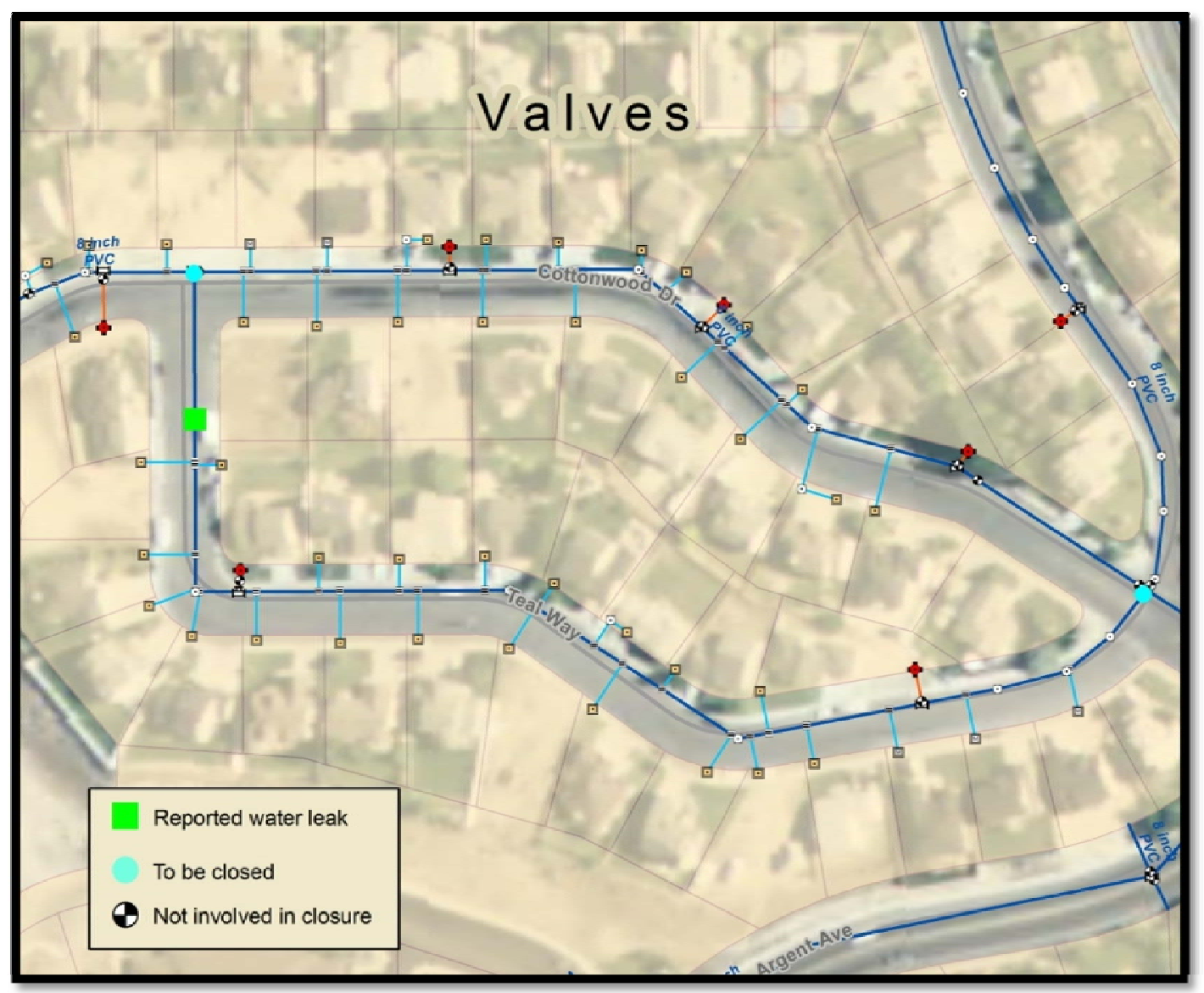

Figure 5-5. Results of tracing to identify valves to be closed

\subsubsection{Find Affected Customers}

With the system valves identified to be closed, it is now possible to locate the customers who will be affected by the maintenance repair of the water main. Building on the system valve isolation trace in the previous analysis in section 5.6, the next steps will help identify customers who will be affected by the valve closure due to repairs on the network (see Figure 5-6). The following is a set of instructions to perform the trace analysis:

1. Select service connection to be selectable

2. Choose the Find connected task

3. Select Solve 


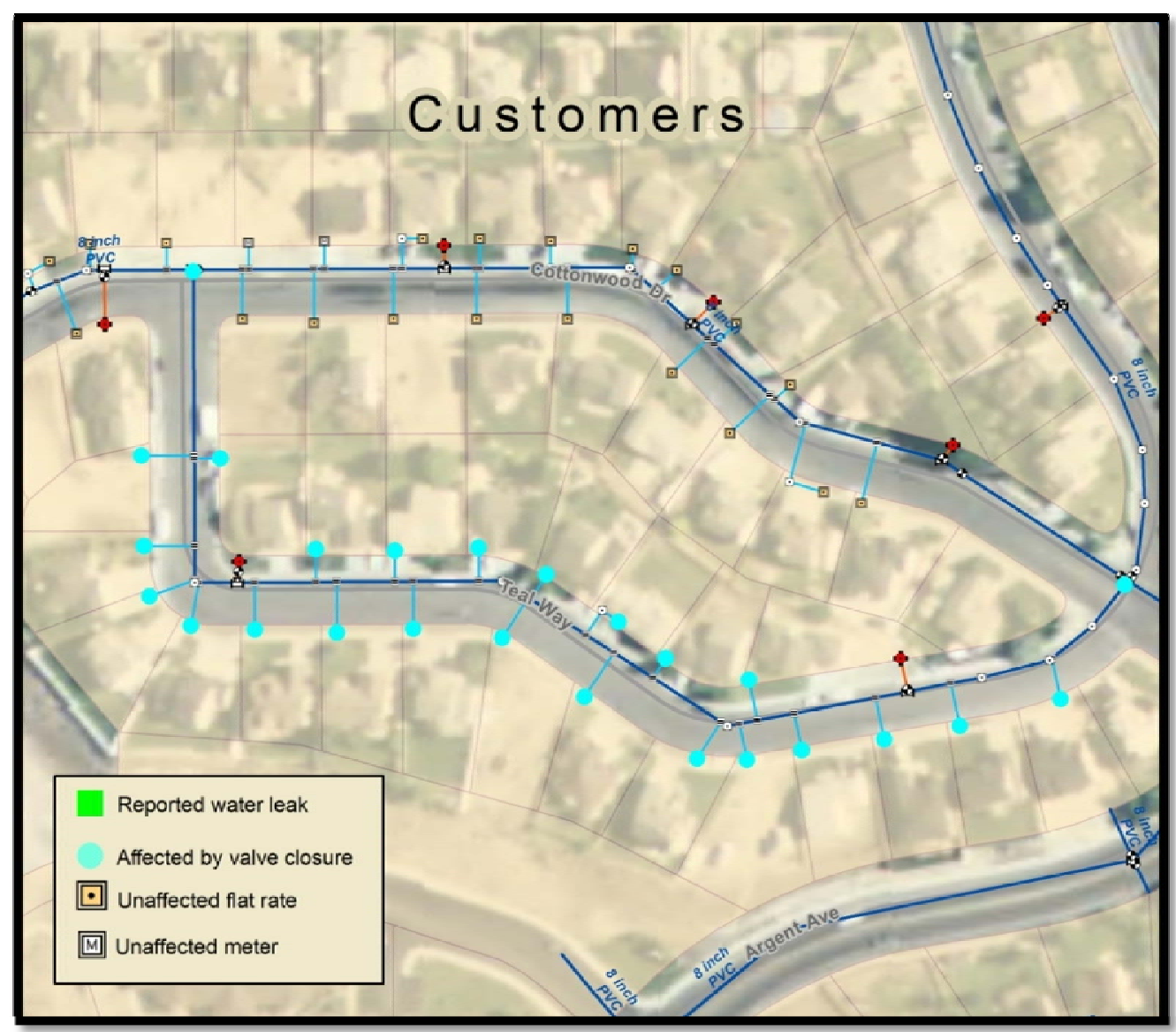

Figure 5-6. Results of tracing network to find customers affected due to valve closure

\subsection{Setting the Flow of Water}

The flow of water is the direction that water travels through in the network. Flow direction is not affected by the course of the edge features in the network. It is the flow direction that is based on the ancillary role of junctions, enabled status of features, and weights assigned in the network (Hijazi, 2004). To apply the flow direction of water sources and sinks must be identified in the network. For this project the pump stations were selected as a source. The pump stations were selected as a source because they drive water through water through the network and away from the pump station itself (ESRI, 2008d). The sinks in the network are the junctions that pull the flow of water through the edges, such as service connections and fire hydrants. In order to set the flow direction the user must:

1. Open the Network Analyst toolbar

2. Navigate to Flow and open drop down menu

3. Choose the Display Arrows

Once the flow is set, the edges in the network have one of the three possible categories of flow direction:

- Determinate 
- Indeterminate

- Uninitialized

The determinate flow of an edge is uniquely determined by the connectivity of the network. The flow is either specified as with or against the direction in which the feature was digitized. The indeterminate flow occurs in a network when the flow direction cannot be determined based on the locations of sources and sinks. The uninitialized flow of an edge occurs when the edges in a network are isolated from the sources and sinks in the network (ESRI, 2008d).

Once the flow is set in the network, the results may refer to the edges as being an indeterminate flow. The reason is because the flow direction is determined by the network features and its properties. Also, the flow directions are heavily based on the connectivity between sources and sink in the network. It would be useful to connect all network features in the network before setting the flow of water. 



\section{Testing and Training}

In order to assure the project would become a success, the client was provided with a series of training sessions. The training was focused to incorporate a variety of the client's data in the ArcGIS environment. Following the initial training sessions, a series of one-on-one training sessions were provided for the engineering department. This training involved an in-depth technical guidance for the main editor, such as step-by-step instructions for maintaining and updating the network. The system was also tested and evaluated to prevent further problems which could occur with the application.

\subsection{Training Sessions}

The training sessions provided the client with a better understanding of the ArcGIS environment. The training material utilized the client's data which consisted of an area located in Northwest Elko. The training data, a prototype dataset, was prepared to test and evaluate the built GIS design. The session included a series of short exercises to allow hands-on experience using buttons and tools in ArcMap: for more information see Appendix C. The outcome of the test session made it apparent what the client wanted from a completed GIS application. The users benefited most when being able to incorporate raster files, CAD data, and adding hyperlinks within the map document. The ability to run an analysis on the water network provided a better understanding of the power of GIS. It demonstrated that GIS is more than a way to view spatial datasets in a digital map environment.

\subsubsection{Client Training}

To accomplish the training demonstration of the project, a classroom was reserved at the Great Basin College campus in Elko, Nevada, on May 2, 2008. The classroom computers had an ArcView 9.2 license and the standard Microsoft Office 2003 software installed. The training session involved two city employees from the Engineering Department. They were trained on the new application and educated on how to:

- Maintain a file geodatabase

- Work with a geometric network

- Georeference as-built drawings

- Hyperlink raster files to features

- Perform trace analysis on the water network

Most importantly, the client was briefed on how to maintain their domestic water network records with the use of GIS. The results of the training helped guide changes needed to be made for the final deliverable of the project.

A one-on-one training was provided for Mr. Tony Ferguson, the city's Senior Engineer. The training was extended over the course of a two week period in the last month of April 2008. The training provided the client with the knowledge to maintain the geodatabase along with the use of the tools provided from off-the-shelf ArcGIS 9.2. Other project deliverables included a database diagram, instructional videos, and a procedure document created to help the client in the maintenance of the GIS. These and 
other resources available from the ESRI community can provide help when technical difficulties arise.

\subsection{Reference Materials}

The client has been provided with a GIS user guide document that will help perform daily tasks and assist in finding answers to frequently asked questions (FAQ's). The document consists of a step-by-step guide to help answer general questions or issues the user may encounter. The procedure document covers material from general ArcGIS tips to more advanced functions, such as performing analysis on the water network. Also, a series of short video clips were produced to help provide support to the visually inclined learners. These videos were made with Camtasia Studio 5 and saved as a .wmv file format that can be played with Windows Media Player. 


\section{Implementation at Client Site}

\subsection{Completed April 2008}

Once the formal training demonstration was provided for the city's engineering department the final geodatabase was completed and delivered to the client. The geodatabase provided the engineering department the ability to edit and populate the database. Mr. Ferguson has been updating attribute information for each of the water network features with the use of reference sources. After a few editing sessions, Mr. Ferguson realized that each network feature would need to be assigned the same attribute information based on their location of a pressurized water zone. Also, the county's parcel dataset covers the entire county and Mr. Ferguson thought it would be convenient to reduce the amount of records stored in the geodatabase by selecting parcels located in and around the city limits. The client has also taken the liberty to load the project geodatabase onto a Toughbook, a laptop pre-loaded with ArcGIS that the EMWD field crew utilizes to view and query the water network data.

\subsubsection{ModelBuilder Tools}

The client requested the ability to update features based on their geographical location of a pressurized water zone. A Set Water Zone tool was created to select a user defined region and the features located within it to be updated. The tool was built in a model using ModelBuilder. A user form first pops-up; the water zones feature class is automatically entered as the polygon to make a selection from (see Figure 7-1). The user only needs to specify the features data source and the zone code for the specific pressure zone to select the features from within. The zones codes are explained in the help window. Since this tool only selects the features within the specified extent of a pressure zone, the user must manually open the attribute table for the selected features and update its operational zone field to the appropriate zone name. 


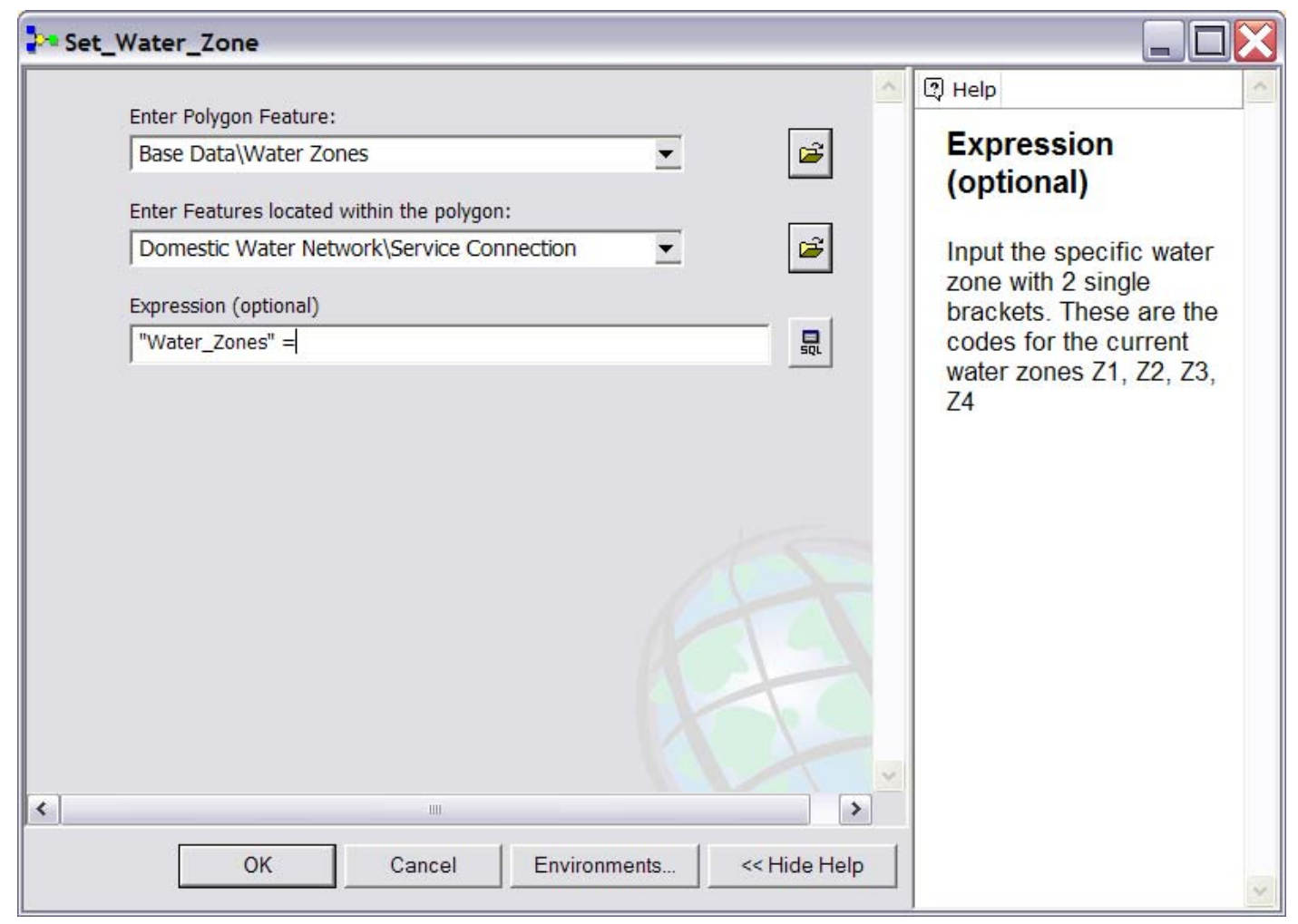

Figure 7-1. Custom tool to set the water zones of features

The client receives an update of county parcels from the Elko County Engineering Department and it is useful to clip the parcels dataset. The data only needs to cover the extent of the proximity of the city limits. The County to City Parcels tool clips the county parcels dataset based on a five mile proximity to the city limits boundary. The tool helps reduce the amount of parcel records stored in the geodatabase. It is not necessary for the client to maintain every parcel record in the county. The tool was built using ModelBuilder which provides an easy to use interface to update the parcels (see Figure 7-2). The tools environments setting are set to place the input data to the county parcels; the location of the city limits dataset for the clip extent; the export feature dataset to place the city parcels data. 


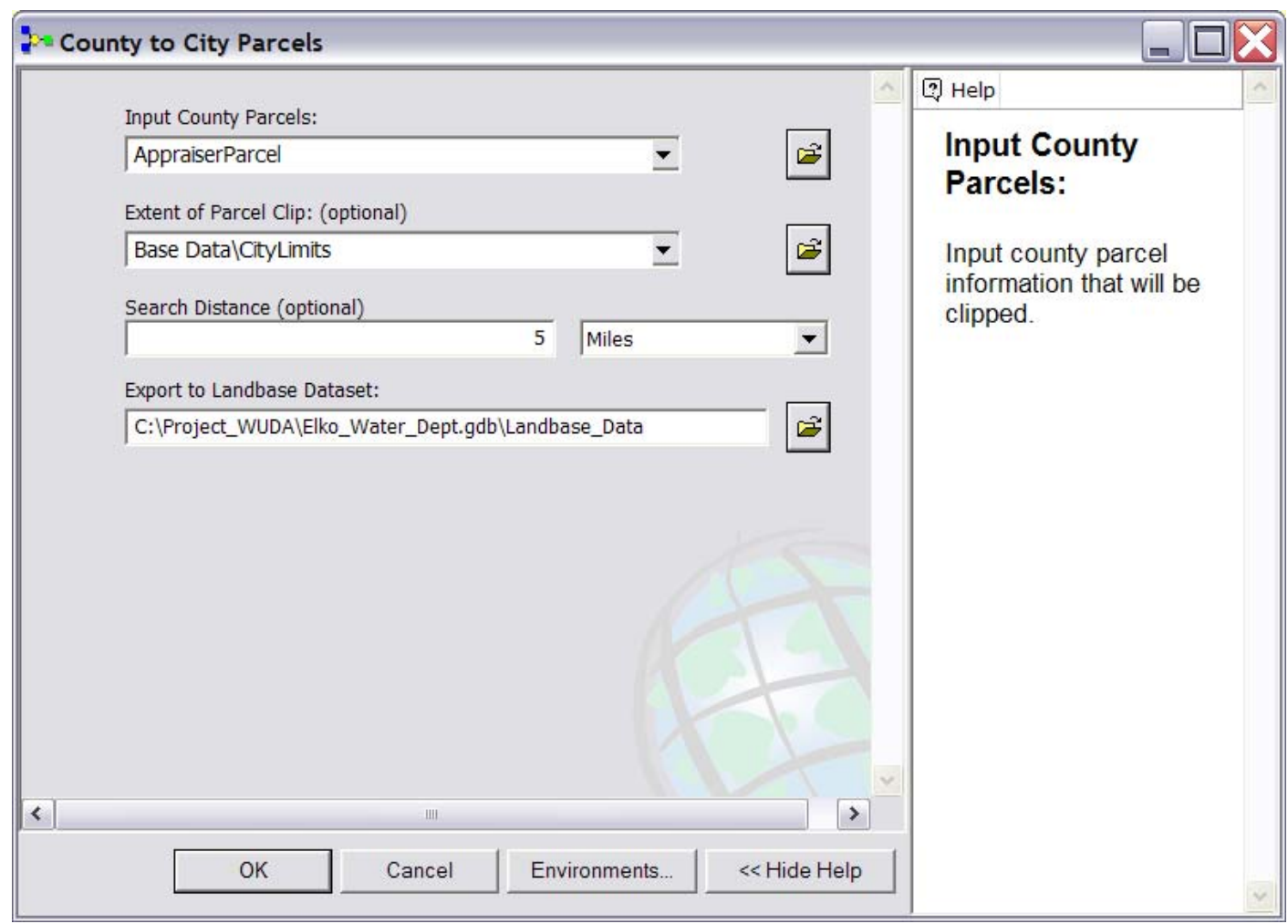

Figure 7-2. Custom tool to clip county to city parcels

\subsubsection{Configure Out-of-the-Box Tools}

The following sets of tools are identified in the system design and are elaborated to show their importance to the maintenance of records in the geodatabase. There are certain procedures used to edit network features, such as the need to move the location of features without affecting the elasticity of other connecting features maintained by the geometric network. The Geometric Network Editing toolbar has a series of tools that are useful to disconnect, connect, rebuild, repair, and verify the geometric network features. For example, when features in the network don't connect, whether a line is overshot or undershot, the edges or junctions are selected and with the toolbar are connected to the rest of the network. It would be illogical to have active pipes or meters dangling in the water network since the flow of water must be present.

The Geometric Network Editing toolbar (see Figure 7-3) is available at an ArcInfo license level in ArcMap. The toolbar should be reviewed by those who will be making edits to the network features in the geodatabase prior to making any major edits.

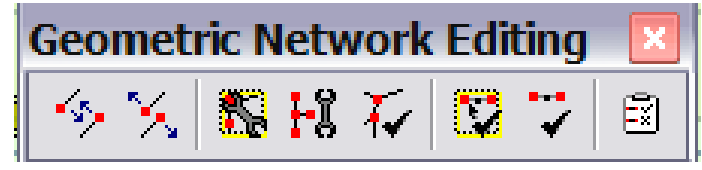

Figure 7-3. The Geometric Network Editing toolbar 
The toolbar is useful for adding or removing the connection of features, checking and repairing features in the geometric network that may contain network build errors.

Features in the network whose geometries are invalid within the context of a geometric network are selected and identified. A list of possible network build errors include:

- Features that have empty geometry

- Edge features that contain multiple parts

- Edge features that form a closed loop

- Edge features that have zero length

To track the service connections records of each customer, the client needed a way to utilize the information stored in the parcels dataset and transfer the data to the service connections feature class. The Attribute Transfer Mapping tool (see Figure 7-4) is used to extract attribute data from one feature to another. The tool transfers data from the source layer, parcels dataset, to the target layer, service connection. The address and Parcel Identification Number (PIN) attribute data is copied and pasted to the location description and APN fields in the service connections. The tool will help reduce data recreation, misspelling, and time spent editing the attributes of each feature.

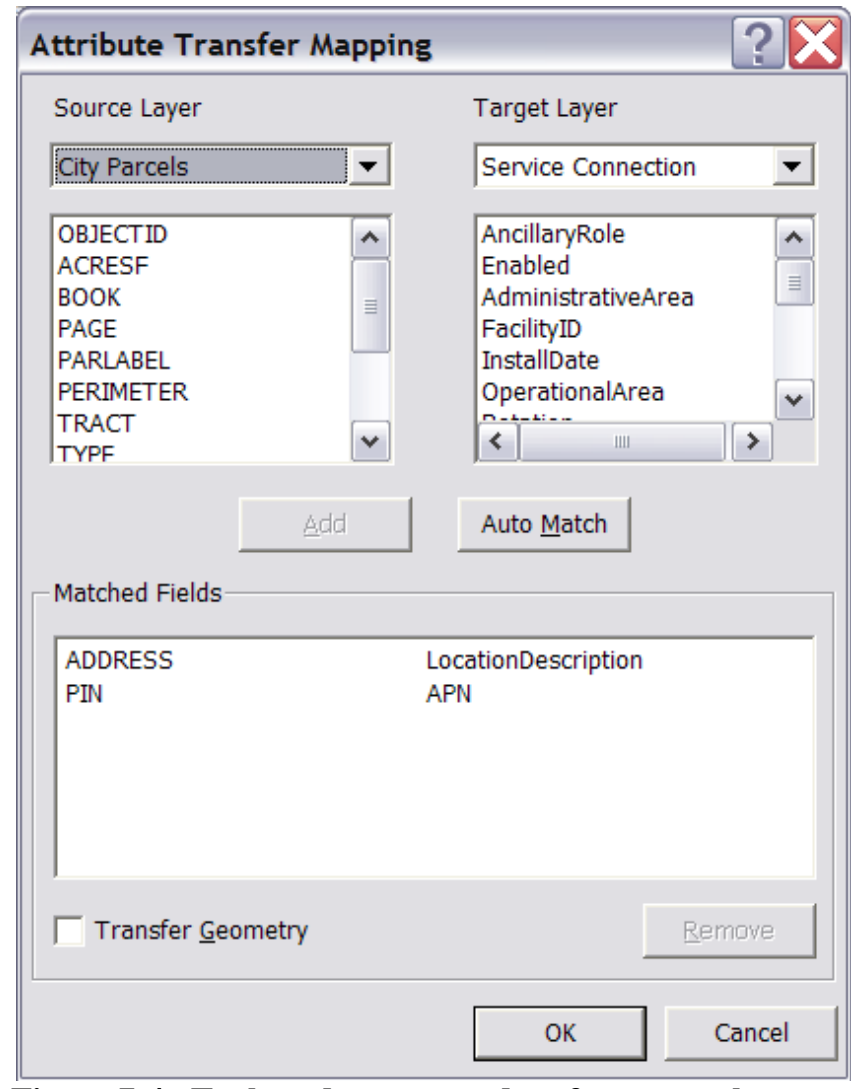

Figure 7-4. Tool used to extract data from parcels to service connections 


\subsection{Further Suggestions}

It is acknowledged that the client is at a beginner level in using the ArcGIS Suite. There are plenty of sources for users to seek help for support and guidance. The following suggestions should be taken into account when the client is in need of guidance with the GIS:

- Utilize ESRI's ArcGIS 9.2 Desktop Help Online: http://webhelp.esri.com/arcgisdesktop/9.2/index.cfm?TopicName=welcome

- Read through the GIS procedures document for guidance

- Seek ad hoc support by email to: Alejandro Quintero@,redlands.edu

- Create weekly meetings with staff about GIS progress and future strides

- Maintain adequate written records of any new changes that may be implemented to future projects

- Keep staff involved with plans and goals of GIS

- Involve key stakeholders on project status

- Seek to incorporate student interns for future work (Great Basin College students)

The client should stay up-to-date with the latest service pack and patches provided on the ESRI support website:

http://support.esri.com/index.cfm?fa=downloads.patchesServicePacks.gateway. The service packs will help fix bugs and issues that may arise. It is useful to check this webpage on a monthly basis as new patches and service packs may be available for download.

Latest service pack from ESRI that is recommended: ArcGIS Service Pack 5 was released on March 26, 2008.

http://support.esri.com/index.cfm?fa=downloads.patchesServicePacks.viewPatch\&PID=1 $7 \&$ MetaID $=1377$

It would also be in the best interest of the client to stay up-to-date with training that is provided by ESRI. There are many virtual classes offered by ESRI to users online. The online classes and other ESRI training classes can be found at: http://training.esri.com/gateway/index.cfm.

The client should review the provided options and seek to better familiarize themselves with the ArcGIS Suite. The ESRI Support Center is the best option to consult when issues arise. The client can consult with me after project completion for help and support, primarily by way of email. Help and support can be managed between the client and myself if needed to help the client resolve post project problems or issues.

\subsection{ESRI Tools}

There are a series of tools available from ESRI that are useful to incorporate for the maintenance of the project geodatabase. The following ESRI tools identified are used to maintain databases and geometric networks. The tools are not necessary for editing the network but are recommend for use to make editing easier to complete. 


\subsubsection{Subsume Multiple Junctions}

The Subsume Multiple Junctions tool is a sample tool available from the ESRI ArcObjects Online. The sample provides the user with the ability to select junctions from multiple feature classes in order to subsume the selected junctions into a target junction feature class. In the case of this project, when selecting one or more orphan junctions in the drawing, the set to the target feature layer selected would then be subsumed to a junction feature class, such as a meter, hydrant, and valve. The tool is enabled when the editor activates an edit session. The target layer must be set to a junction feature. The junction features within the selection set are subsumed by the editor's current target layer. The tool can be found at:

http://edndoc.esri.com/arcobjects/8.3/Samples/Editing/Working $\% 20$ with $\% 20$ Network $\% 2$ 0Features/Subsume\%20Multiple\%20Junctions/Multiple\%20Subsume.htm

\subsubsection{Geodatabase Designer 2}

The Geodatabase Designer 2 is a set of tools that document and exchange geodatabase schema. The user can import/export a geodatabase, object class, domains, geometric network, or topology to and from an XML format. The tool also includes an editor for the geometric network connectivity rules which provides an easy to use graphic interface to add and remove junction and edge rules. The tool is available from ESRI ArcScripts at:

http://arcscripts.esri.com/details.asp?dbid=13484 


\section{Project Deliverables}

A collection of training videos have been created and are located on the MIP data disc in the TrainingVideos folder. The videos can be viewed by double clicking on the training video file. A help request form was created to provide the client a way of communicating problems encountered with the project files. The file is located on the MIP data disc in the HelpRequest folder.

\subsection{Introduction and Purpose}

The training demonstration videos were created using the trial version of Camtasia Studio 5.0 by TechSmith (see http://www.techsmith.com/camtasia.asp for more information). The software program captures on-screen recordings including mouse movements and audio clips. Once a video is completed the author may edit the video by adding callouts, titles, watermarks, additional text, and a variety of other functionality to improve the quality of the video. The videos made for this project are saved as a .wmv file that can be viewed in Windows Media Player.

The purpose of the training videos is to provide training about ArcGIS functionality in a series of short video recordings. It will provide users the ability to visually comprehend training demonstrations and provide the ability for the consumer to review the demos in a relatively short period of time. The training demonstrations videos include demos on how to:

- Georeference raster files

- Utilize CAD data in ArcMap

- Perform a valve isolation analysis

- Find affected customers from valve isolation

The videos are subject to use by the client. They were made with the intention to stimulate learning of the tools and analysis functions available from ArcGIS. The idea is to educate users of the tools found within ArcMap, learned from the creation of this project, and passed onto the client who will continue to use the ArcGIS suite to update and maintain the project geodatabase and map document.

A help request form was created with Adobe Acrobat, with the create form tool. The form was created to provide the client with a method of documenting questions, concerns, or problems by printing or emailing the form. For more information about the help request form see Appendix D. 



\section{Summary and Future Work}

The project has matured from its infancy stage to a full functioning GIS application for the City of Elko, Nevada. Data initially stored in AutoCAD files, Excel documents, and scanned paper maps have been explored and incorporated into a geodatabase. As a result of the data conversion, moving various data sources into a GIS, the client has become aware of incomplete data sources and missing information. Locating the missing information and determining the data sources have been determined to be necessary to incorporate into the GIS workflows. Geodatabase updates are critical to provide an accurate representation of the domestic water network, as out-of-date information can pose a problem during an emergency situation.

The most efficient data source is found on the client's as-builts. The as-builts contain a significant amount of data in the drawings that can be extracted and placed into the geodatabase. Other sources of data identified are utility plans, service cards, field crew members, and aerial imagery used to update features and its attribute information. Providing a hyperlink has been a practical solution by incorporating scanned as-builts files into the GIS and referencing them to its related network features. The hyperlinks provide immediate access to original as-built drawings from which data was created. The main advantage of using a GIS is being able to provide information on-screen rather than having to search through large rolls of plans or dispersed CAD drawing files.

The GIS application has enabled the city to create, maintain, and distribute spatial data more efficiently than ever. The client has been able to provide information about the domestic water utility network to other employees by printing maps or providing city employees with the GIS database. The functionality available in ArcGIS has provided the client the ability to perform spatial queries and analysis from the data to find answers within minutes, rather than the days or weeks when using AutoCAD and paper maps, which has added interest to other employees at the city about GIS and its value to the city. Since May 2008 the client has had the opportunity to edit the network drawing and populate the database with information. Table 9-1 illustrates the changes in the number of features collected in the database. The data layers have since been modified which either increased or decreased the number of features stored in the geodatabase. 


\begin{tabular}{l|lll} 
Table 9-1. Update count of GIS data layers as of June, 24 2008 & \\
\hline Data Layer & Original Count & Data Source & Updated Count \\
\hline Service Connection & 1122 & $\begin{array}{l}\text { UTILITY-MAP- } \\
\text { Master.dwg }\end{array}$ & 3106 \\
System Valve & 2639 & $\begin{array}{l}\text { UTILITY-MAP- } \\
\text { Master.dwg } \\
\text { UTILITY-MAP- }\end{array}$ & 2852 \\
Fitting & 0 & $\begin{array}{l}\text { Master.dwg } \\
\text { UTILITY-MAP- }\end{array}$ & 4968 \\
Hydrant & 942 & $\begin{array}{l}\text { Master.dwg } \\
\text { UTILITY-MAP- }\end{array}$ & 2042 \\
Network Structure & 17 & $\begin{array}{l}\text { Master.dwg } \\
\text { UTILITY-MAP- } \\
\text { Master.dwg }\end{array}$ & 4859 \\
Distribution Main & 5405 & $\begin{array}{l}\text { UTILITY-MAP- } \\
\text { Master.dwg }\end{array}$ & 4139 \\
Lateral Line & 3947 & $\begin{array}{l}\text { UTILITY-MAP- } \\
\text { Master.dwg } \\
\text { UTILITY-MAP- }\end{array}$ & 11 \\
Water Zones & 12 & $\begin{array}{l}\text { Master.dwg } \\
\text { Elko County Mapping } \\
\text { Department }\end{array}$ & 7,403 \\
City Boundary & 2 & &
\end{tabular}

The maintenance and operations of the EMWD have improved access to information about their water network that has sparked interest in enhancing the capabilities of the built project. The EMWD crew would like to incorporate the capabilities of Computerized Maintenance Management System (CMMS) to better manage an inventory list of materials used for a particular job, recording the location of in-house material, and determining when materials should be purchased. The information would allow the city EMWD to plan and execute better management decisions. CMMS and other similar software applications provided by third party software vendors are further mentioned in section 9.1.4.

Feedback from the EMWD field crew extends the efforts initially planned for this project. The ability to provide city employees with the information they need without long turnaround times and adding the ability to analyze the network dataset has provided the employees with the information needed within minutes. The built GIS application has inspired confidence and reliability from its users and future efforts are being addressed by the client to incorporate GIS for other departments. The system has provided the ability to produce answers through analysis on the network within minutes instead of hours or days.

\subsection{Future Work}

The maintenance of the GIS will need plenty of attention. Errors can affect the overall structure of the database which lead to problems and inconsistencies of future updates. It is highly recommended to create frequent backups of the database and to document 
changes made to the system. This will assist in resolving any future problems that may possibly occur. Database maintenance alone cannot keep a GIS fully functional; it is recommended the client stay up-to-date with regular updates of the software and hardware technology. Since GIS databases are dynamic and change on a daily basis it would be advisable to maintain a formal procedure document of comprehensive maintenance and updating activities and followed up by GIS users and the consumers.

\subsubsection{Cleaning the Drawing}

There are a few set of problems identified in the drawing file due to the data conversion from AutoCAD, such as missing and misrepresented data. Missing and existing data will need to be corrected so that the geometry files are represented appropriately in the drawing. Figure 9-1 represents a main line with an arc and orphan junctions that is supporting the network connectivity. The lines files drawn as arcs in AutoCAD are used to represent pipes that are situated above another utility line, such as domestic water or sewer line. In a GIS, the geometry of the features should represent the network as they are in the real-world.

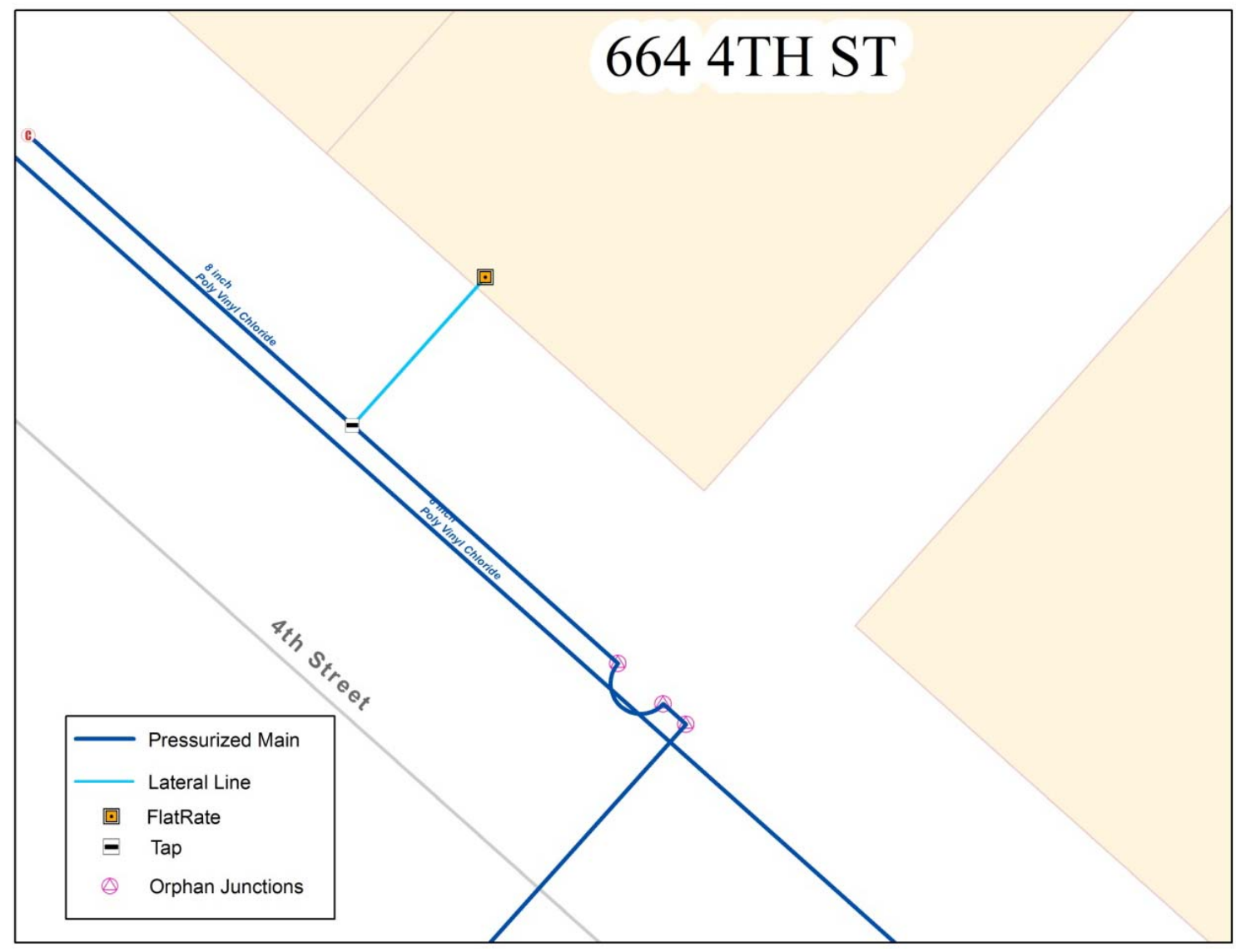

Figure 9-1. Arcs and orphan junctions that should be removed in drawing 
Orphan junctions that reside in the network need be replaced with a junction feature, i.e. meter, hydrant, fitting, or valve. Once the junction features are removed the water network will better resemble the built physical network.

\subsubsection{Updating Size Fields}

Junction fittings that are updated during editing need to follow a convention so the sizes of each fitting are captured systematically. Fittings - tees, taps, and crosses - have designated fields for the fittings sizes used to record the individual record of each fitting in the network. For tees updated in the network they should be updated appropriately by field as indicated in Figure 9-2.

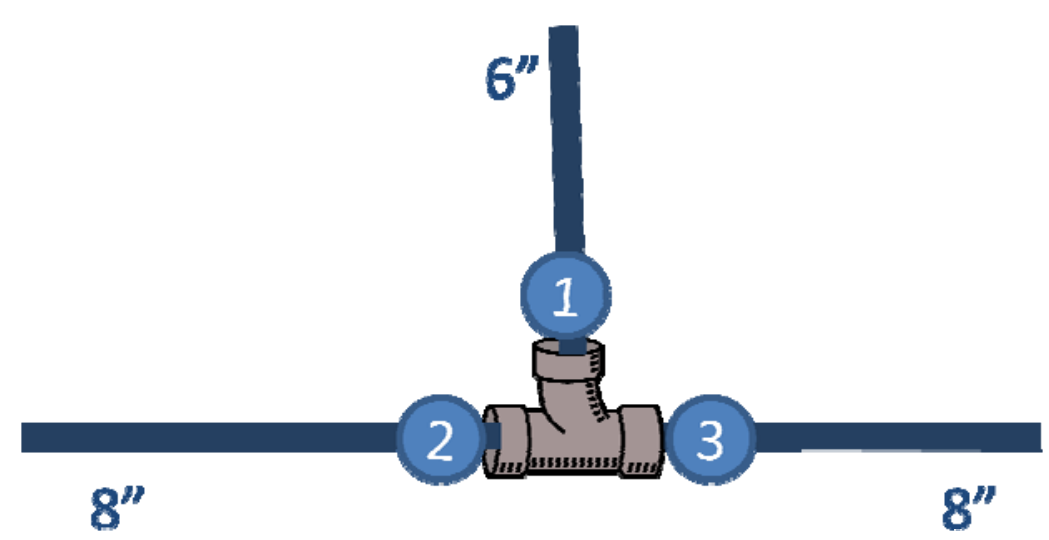

Figure 9-2. Diameter reference for tee fitting

Setting the sizes of other fittings, such as for taps and crosses should follow a similar convention as used with the tee fitting.

\subsubsection{Customer Notification Forms}

The find connected trace analysis has been identified to find valves that need to be closed and customers to be affected in the event of maintenance repair. To add more functionality to the trace analysis it would be good to create a form that contains information to notify customers when their water services will be temporarily discontinued. There are two methods in ArcMap to produce the reports: one is the basic create form, the second is the create crystal report function that can be found under the tools and reports tab. Custom templates can be created and saved to further simplify the process of creating and reusing reports.

\subsubsection{Third Party Applications}

The integration of third party software can help benefit the use of data collected in a GIS. There are a variety of software applications that perform work order and asset management (CMMS/EAM - Computerized Maintenance Management System/Enterprise Asset Management). The following is a list of some known vendors and their website: 
- Cityworks

http://www.azteca.com/

- GBA Master Series

http://www.gbams.com/

- Hansen

http://www.hansen.com/

- Maximo

http://www-306.ibm.com/software/tivoli/products/maximo-asset-mgmt/

Each of these software products have some application programming interface that can be used to build interfaces with GIS. An asset can be selected in the application and zoomed-to in ArcMap or the asset can be selected in ArcMap and corresponding information from the CMMS can be retrieved. More research should be conducted before applying anyone of these software applications as it may involve complicated software integration and a high level of experience to operate. 



\section{References}

Bedford, M. (2004). GIS for Water Managment in Europe. Redlands, California: ESRI Press.

Benjamin, C. O., \& Khawaja, Y. K. (1996). A Quality Function Deployment Framework for Effective Transfer of AM/FM/GIS Information Technologies to Small Communities. URISA Journal, 8(1).

DeGironimo, E. (2002). The Key to the Vault: Mohawk Valley Water...Paper to Geodatabase Pilot Project. Water Writes, Fall 2002 (GIS for Water/Wastewater).

ESRI. (2001). Water Utilities. Redlands, California: ESRI Press.

ESRI. (2002). A Small City Builds ArcGIS Water Utilities Geodatabase From the Ground Up. Water Writes, Fall 2002(GIS for Water/Wastewater).

ESRI. (2003). GIS Manages Small Town, USA: A Comprehensive Look at the City of Bellingham Geographic Information System. Water Writes, Summer 2003 (GIS for Water/Wastewater).

ESRI. (2008a). Water Utilities Data Model. Retrieved January 3, 2008, from http://support.esri.com/index.cfm?fa=downloads.dataModels.filteredGateway\&d $\operatorname{mid}=16$

ESRI. (2008b). GIS for Water and Wastewater. Water Writes Retrieved November 15, 2007, from http://www.esri.com/industries/water/news community/newsletter.html

ESRI. (2008c). ArcGIS 9.2 Desktop Help. Retrieved March 15, 2008, from http://webhelp.esri.com/arcgisdesktop/9.2/index.cfm?TopicName=Geometric net work connectivity rules

ESRI. (2008d). ArcGIS 9.2 Desktop Help. Retrieved April 12, 2008, from http://webhelp.esri.com/arcgisdesktop/9.2/index.cfm?TopicName=Flow direction in a geometric network

Fleming, C. (Ed.). (2005). The GIS Guide for Local Government Officials (1st ed.). Redlands, CA: ESRI Press.

Governmental Accounting Standards Board. (2000). Asset Management and GASB 34 Challenge or Opportunity? Retrieved July 12, 2008, from http://www.gasb.org/repmodel/030601.pdf

Hijazi, I. H. (2004). Storm Drainage Network for the City of Redlands, California. University of Redlands.

Maneva, P. (2004). Development of a GIS for the University of Redlands Domestic Water Network. Redlands, California: University of Redlands.

Mattix, M. (2006). Converting CAD Data. ArcUser(January-March 2006).

Muller, J. C. (1985). Geographic information systems: A unifying force for geography. The Operational Geographer, 8, 41-43.

National Research Council. (1993). In Our Own Backyard: Principles for Effective Improvement of the Nation's Infrastructure. Washington D.C.: National Academies Press.

National Research Council. (1996). Measuring and Improving Infrastructure Performance. Washington D.C.: National Academies Press.

Nevada Department of Transportation. (2008). GASB 34 - Governmental Accounting Standards Board Statement 34. 2008, from http://www.nevadadot.com/about/GASB34/pdfs/WhatIsGASB34.pdf 
Shamsi, U. M. (2005). GIS Applications for Water, Wastewater, and Stormwater Systems. Boca Ralton, Fl: CRC Press.

Tomlinson, R. (2007). Thinking About GIS: Geographic Information System Planning for Managers (3rd ed.). Redlands, CA: ESRI Press.

U.S. Census Bureau. (2006). 2006 Population Estimates. 2008, from http://factfinder.census.gov/servlet/SAFFPopulation? event=ChangeGeoContext \&geo $\mathrm{id}=16000 \mathrm{US} 3222500 \&$ geoContext $=\&$ street $=\&$ county $=E L K O \&$ cityTo wn $=$ ELKO\& state $=04000$ US32\& zip $=\&$ lang $=$ en \& sse $=$ on \&ActiveGeoDiv $=\&$ useEV $=\& p c t x t=f p h \& p g s l=010 \&$ submenuId $=$ population $0 \& d s$ name $=$ null $\&$ ci

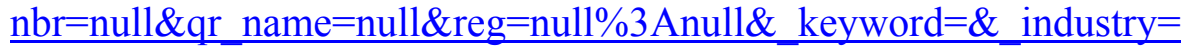

U.S. Geological Survey. (2008). Water Science for Schools. Retrieved May 10, 2008

Water Environment Federation. (2005). GIS Implementation for Water and Wastewater Treatment Facilities (1 ed.). New York, NY: McGraw-Hill.

Wilson, J. P., Mitasova, H., \& Wright, D. (2000). Water Resource Applications of Geographic Information Systems. URISA Journal 12(2), 61-62.

Zeiler, M. (2004). Modeling Our World: The ESRI Guide to Geodatabase Design. Redlands, CA: ESRI Press. 


\section{Appendix A}

\section{Georeference data files in ArcMap}

The following is a set of instructions to georeference raster and CAD files within the ArcGIS environment.

\section{How to georeference raster files in ArcMap}

1. Add raster to ArcMap

2. Zoom to file layer. Right click layer in table of contents and zoom to layer

3. Familiarize yourself with the project area

4. Locate project area with the use of the base data. It is recommended to create a bookmark when locating project area

5. Once project area is found, in georeferencing toolbar select Fit To Display

The Fit To Display button will move the raster image to a visible area on your screen. This will help make it easier to georeference the raster file.

6. Use control points to adjust image. Go from raster file (unknown) to base data (known) location.

7. Select at least 3 points. Make sure to keep the RMS under 1.5

8. Select the update Georeferencing which creates a world file for the raster

9. Use the Rectify tool. This tool creates a new image with a projection and builds pyramids. It is recommended to keep the default cell size and resample type.

Change the format to TIFF, the name, and the location to store the new raster file (see Appendix Figure 1A).

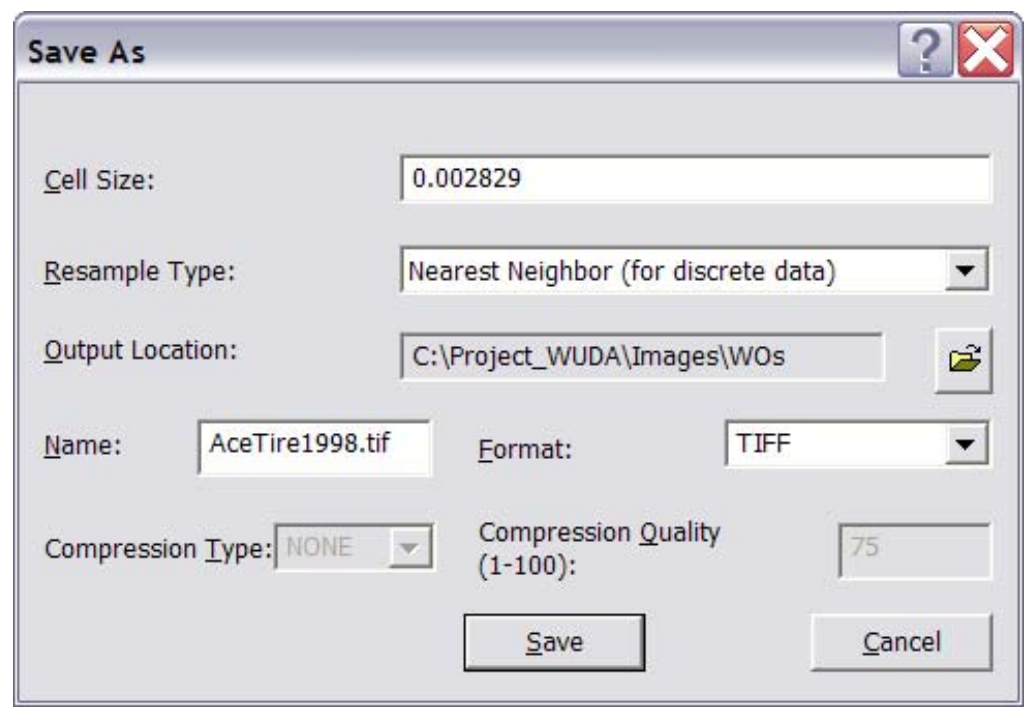

Appendix Figure 1A. 
10. Select save to complete georeference process

\section{How to georeference CAD files in ArcMap}

1. Add CAD drawing to ArcMap

2. Zoom to file layer. Right click layer in table of contents and zoom to layer

3. Familiarize yourself with the area of study

4. Locate project area with the use of the base data. Recommended to create a bookmark

5. On georeferencing toolbar select add control points

6. Make sure to have the layer you want to georeference selected in layer window

7. (Optional) Turn off unnecessary layers. Identify layers you want to view only

8. Then in table of contents select the layer properties. In group layer properties choose properties (see Appendix Figure 2A)

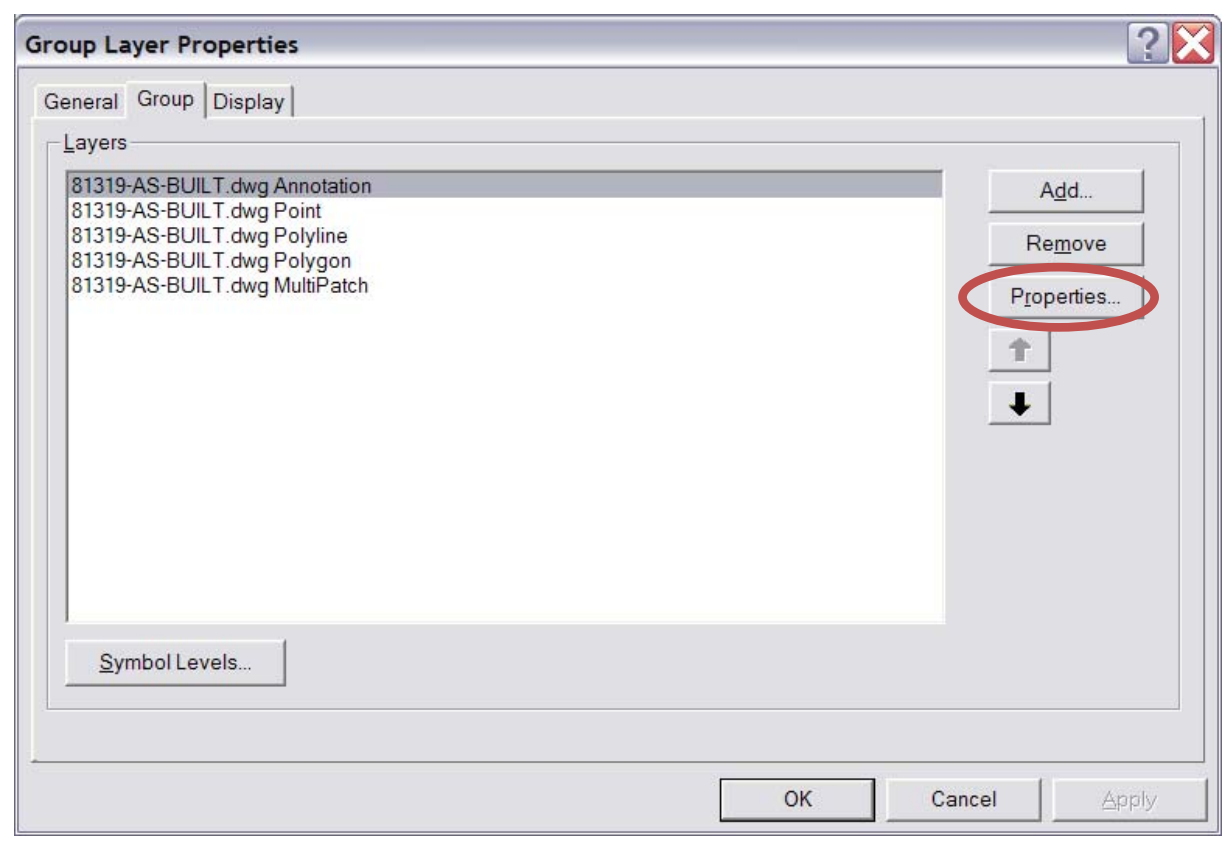

Appendix Figure 2A.

9. Then under Drawing Layers tab choose layer to enable or disable. Then select Apply to Dataset (see Appendix Figure 3A) 


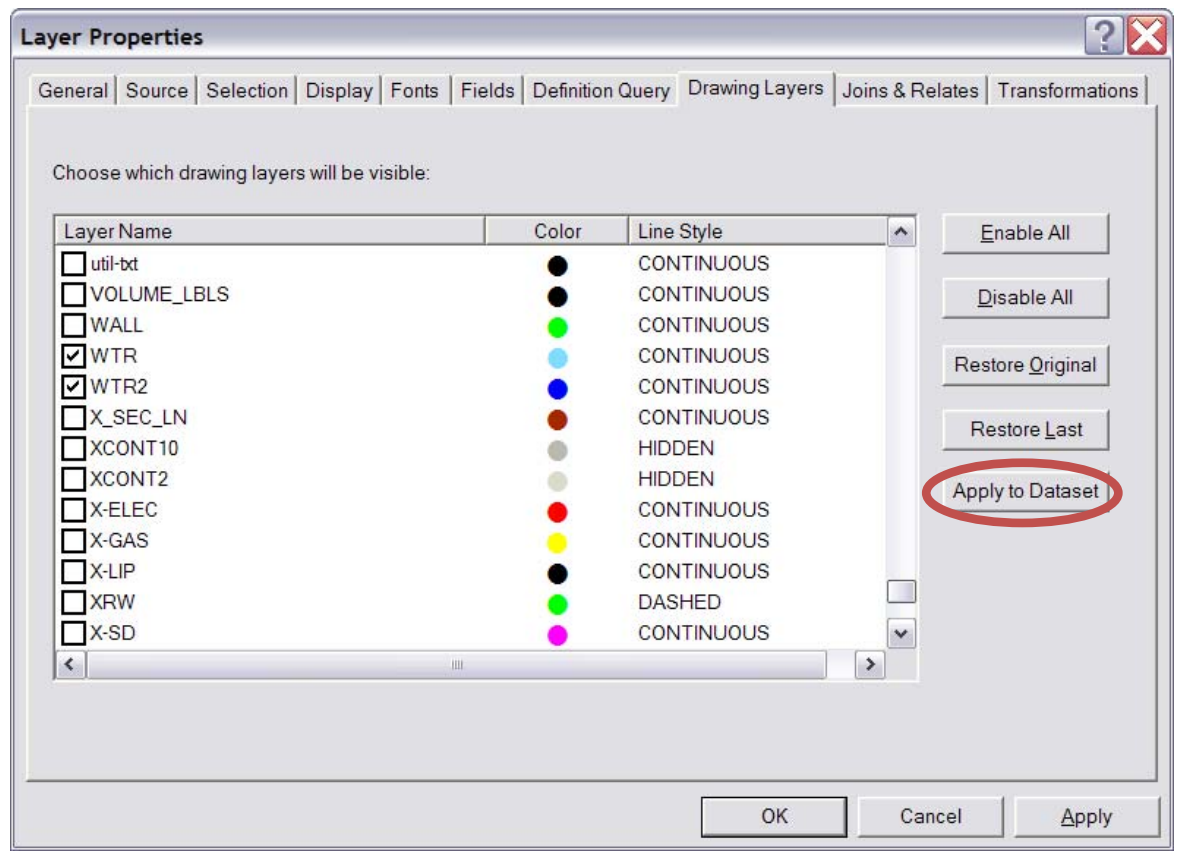

Appendix Figure 3A.

10. Then select $\mathrm{OK}$ to the next few dialog boxes to exit

11. Make sure to properly set up your snapping environment on base and CAD data

12. Select two known points ( $1^{\mathrm{ST}} \mathrm{SW}$ and $2^{\mathrm{ND}} \mathrm{NE}$ preferably) in CAD drawing.

Select first point from CAD file (unspecified) to base data (known) location.

13. In georeferencing tool bar select Update Display.

14. Finally, select the Update Georeferencing. This step will create a world file that must be located in same folder as the CAD file

15. . The CAD file is now aligned with the rest of the GIS data. 


\section{Appendix B}

\section{Managing Hyperlinks in ArcMap}

There are two ways to hyperlink data in ArcMap such as, setting a field-based hyperlink and/or a dynamic hyperlink. A designated field has been reserved in the Pressurized Mains feature class to support a field-based hyperlink. Relative paths should be stored in the field to provide access to other users who may want access to the hyperlinked files but don't have access to the main editors network resources. The dynamic hyperlink tool could be used to add additional documents to the water mains or other features in the map document. Note: Features that are dynamically linked are saved to the current map document and not saved in individual features. The following are a set of steps to make use of hyperlinks in ArcMap.

Set up the hyperlink base path file name for field-based hyperlinks by:

1. Select File $\rightarrow$ Document Properties

2. Insert the file path name (ex. C:|Project_WUDA\Images) First, The Drive Letter; Second, Folder Name; etc....

3. Choose the feature with field-based hyperlink (ex. Pressurized Main)

4. Right Click feature $\rightarrow$ Select Properties

5. Choose Display Tab $\rightarrow$ Check Support Hyperlink using field

6. Choose field designated for hyperlink $\rightarrow$ Select radio button Document $\rightarrow$ Ok (see Appendix Figure 4B) 


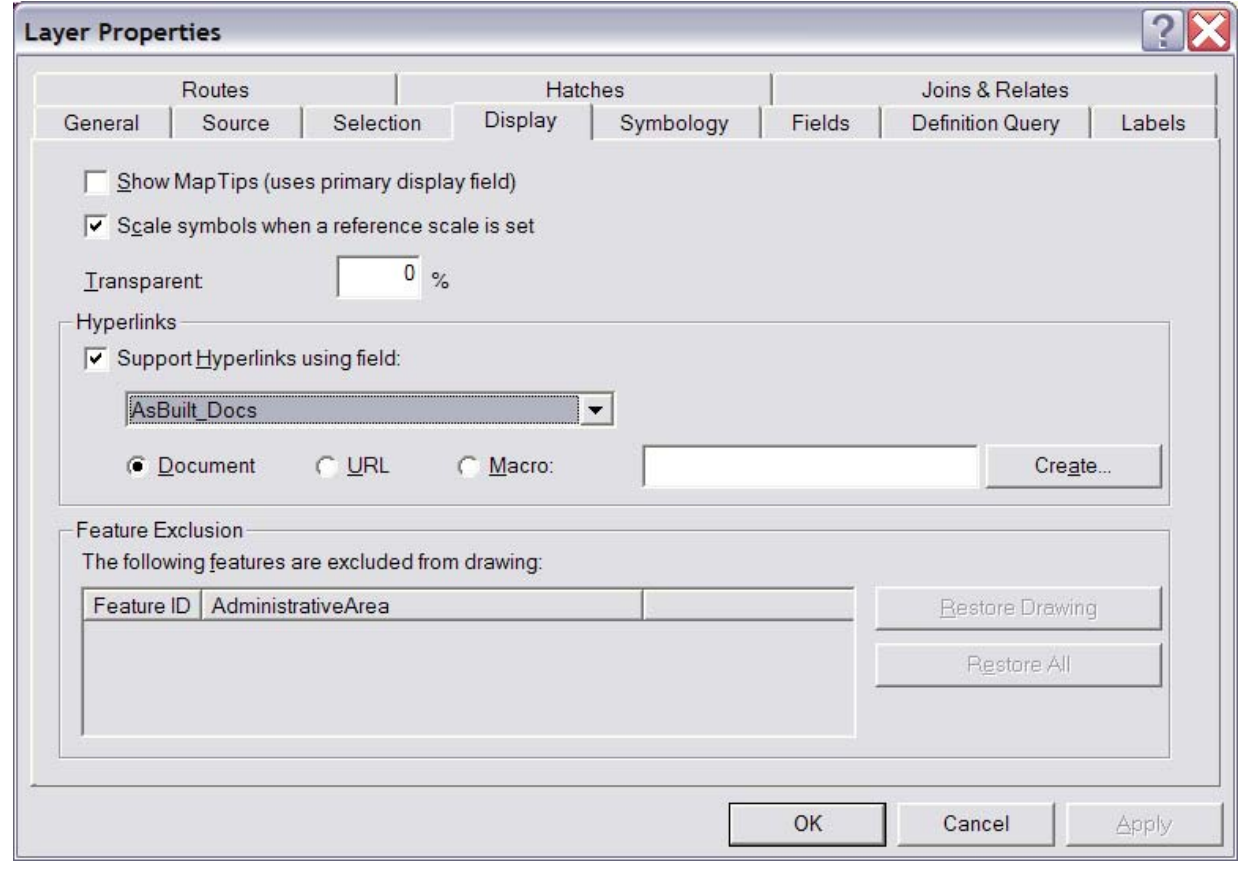

Appendix Figure 4B.

These steps will allow the hyperlink tool to activate and highlight features that have a hyperlink associated to it in its attribute table. To add a field-based hyperlink file name in the attribute table the editor can simply copy and paste document paths from Windows Address Bar to the features field in ArcMap during an active session.

To access the features hyperlink:

1. Make visible the layer to be identified in TOC

2. Click on the hyperlink tool

All visible features that have a field-based hyperlink will be highlighted in blue, default color.

3. Select a feature

Once feature is clicked the hyperlink becomes active

For more information on managing hyperlinks in ArcMap please use the following online resource:

http://webhelp.esri.com/arcgisdesktop/9.2/index.cfm?TopicName=Adding_hyperlinks_to features 


\section{Appendix C}

\section{Training Demonstration Overview}

\section{Training Demo Checklist}

A series of exercises were developed to help make users familiar with the ArcGIS environment. The following are a set of demonstrations provided during the test phase:

1. Getting to know ArcMap

2. How to begin editing features

3. Georeference scanned images

4. Associate photos with features

5. Set-up hyperlink

a. Associate tiff's to features

b. Enable hyperlink

6. Join table to features

7. Calculate fields

a. Data from table to another

8. Learn how to set up Attribute Transfer tool

9. Utilize existing data sources

a. CAD an Raster data sources

10. Add an ArcToolbox

a. Run custom made Models

11. Customize Interface

a. Add and remove buttons

12. Scale dependencies

13. Importing CAD drawings

a. Create .wld and .prj file

14. Using the Geometric Network Editor

a. Connect, Disconnect, and Verify Connectivity

15. How to find valve shut offs

16. Learn who will be affected by the valve closure

17. Viewing maps in the Map Layout View

18. View in ArcCatalog
a. Database Design
b. Geometric Rules
c. Fields, domains, and metadata

19. Fill out a help request form

20. View available resources available at ESRI.com
a. Scripts
b. Data models 

c. Online help and treads

\section{The following evaluation was given to client after training demonstration to determine built prototype GIS project.}

Please take a moment to fill out this course evaluation.

What did you think of the training demo course?

What was the most useful part of the course to you?

What did you find most useful during the training (ex. Using a certain tool or function)?

Do you think ArcGIS will help you in your daily work routine? How does it help in terms of mapping compared to AutoCAD?

How could this training demo be improved in your opinion? 


\section{Appendix D}

\section{Help Request Form}

The client was provided with a help request form in case there were any issues encountered while working with the project files.

A form was created with the use of Adobe Acrobat to help support problems that the client may encounter. The form was designed with the use of fields, radio buttons, and text boxes for easy to use and returns processing. The form includes a button that will email or print the form. This form will be sent to Alejando_Quintero@,redlands.edu when emailed (see Appendix Figure 5D) 


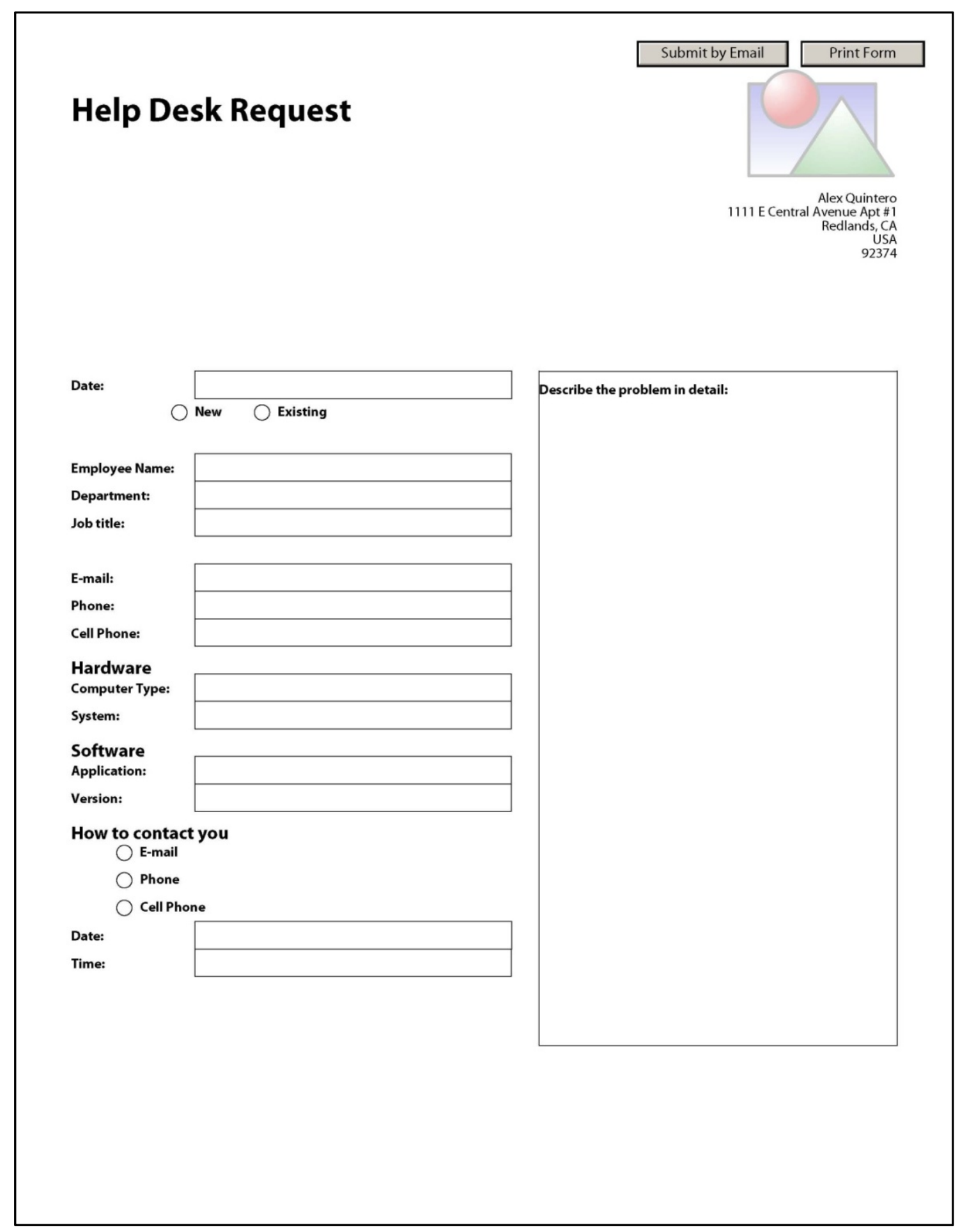

Appendix Figure 5D. 